\title{
Review Article \\ Proteomic Approaches in Biomarker Discovery: New Perspectives in Cancer Diagnostics
}

\author{
Petra Hudler, Nina Kocevar, and Radovan Komel \\ Medical Centre for Molecular Biology, Institute of Biochemistry, Faculty of Medicine, University of Ljubljana, \\ Vrazov trg 2, 1000 Ljubljana, Slovenia \\ Correspondence should be addressed to Petra Hudler; petra.hudler@mf.uni-lj.si and Radovan Komel; radovan.komel@mf.uni-lj.si
}

Received 30 August 2013; Accepted 8 October 2013; Published 14 January 2014

Academic Editors: P. Cassoni and L. Messerini

Copyright (C) 2014 Petra Hudler et al. This is an open access article distributed under the Creative Commons Attribution License, which permits unrestricted use, distribution, and reproduction in any medium, provided the original work is properly cited.

Despite remarkable progress in proteomic methods, including improved detection limits and sensitivity, these methods have not yet been established in routine clinical practice. The main limitations, which prevent their integration into clinics, are high cost of equipment, the need for highly trained personnel, and last, but not least, the establishment of reliable and accurate protein biomarkers or panels of protein biomarkers for detection of neoplasms. Furthermore, the complexity and heterogeneity of most solid tumours present obstacles in the discovery of specific protein signatures, which could be used for early detection of cancers, for prediction of disease outcome, and for determining the response to specific therapies. However, cancer proteome, as the end-point of pathological processes that underlie cancer development and progression, could represent an important source for the discovery of new biomarkers and molecular targets for tailored therapies.

\section{Introduction}

Modern molecular methods have in the last few decades paved their way into clinical diagnostic laboratories. The majority of these novel techniques in cancer diagnostic are based on detection of mutations on the DNA level or aberrant gene expression, relying on quantification of mRNA transcripts. Genetic techniques provide information about specific and subtle genetic changes, which have been quite useful in the identification and diagnosis of certain carcinomas, lymphomas, and leukaemia [1]. Compared to the genome or even transcriptome, proteome is much more complex and dynamic. Since proteins are the actual functional molecules in the cell and represent actual conditions, measuring them as a part of the diagnosis could be an advantage in detecting pathological conditions. A myriad of protein biomarkers is already in use in clinical diagnostics (Table 1); however, the methods used for their detection and evaluation are mostly well established techniques, which are decades old, such as serum protein electrophoresis, Western blot, enzyme-linked immunoassays (ELISAs), and a few other immuno-based assays, including methods relying on fluorescence microscopy and flow cytometry. A few of the better equipped laboratories also routinely use liquid chromatography mass spectrometry (LC-MS/MS) for the detection of small molecules, which include amino acids and biogenic amines [2,3]. MS measurements of proteins and peptides are currently more suited for protein biomarker research, due to technical complexity of the methods, which are not yet suitable for routine diagnostic laboratories, time required to perform the analyses, costs associated with the acquirement of new equipment and training of personnel, lack of thorough analytical and clinical validation of the methods and proteins associated with the particular type of cancer, and finally, problems associated with the sensitivity of the testing for specific rare proteins in protein rich clinical samples, such as plasma, serum, faeces, or saliva $[4,5]$.

Typical molecular biomarkers currently used in clinical setting are proteins, specific variations in the DNA sequence (germline or somatic), abnormal methylation patterns, aberrant transcripts, miRNAs, or other biological molecules, such as lipids and metabolic products. They can be used to evaluate 
TABLE 1: Selection of commonly used blood molecular and protein biomarkers for the management (diagnosis, monitoring recurrence/detecting metastatic spread, and selection of suitable treatment/monitoring treatment response) of cancers in clinical practice.

\begin{tabular}{|c|c|c|c|c|}
\hline Type of cancer & Tumour biomarkers & Type of test & $\begin{array}{l}\text { Additional } \\
\text { biomarkers }\end{array}$ & Type of test \\
\hline Lung cancer & $\begin{array}{l}\text { NSE, TPA, and CEA } \\
\text { (large-cell carcinoma, } \\
\text { small-cell carcinoma) } \\
\text { CEA, TPA (adenocarcinoma) } \\
\text { SCC, TPA (squamous cell } \\
\text { carcinoma) }\end{array}$ & $\begin{array}{l}\text { Immunoassay, ELISA, RIA, } \\
\text { and magnetic-bead based } \\
\text { chemiluminescence enzyme } \\
\text { immunoassay }\end{array}$ & Ferritin & $\begin{array}{l}\text { Immunoassay, ELISA, } \\
\text { and RIA }\end{array}$ \\
\hline \multirow[t]{2}{*}{$\begin{array}{l}\text { Breast cancer, } \\
\text { sporadic }\end{array}$} & $\begin{array}{l}\text { CA } 15-3, \text { CA } 27-29, \text { MCA, and } \\
\text { CEA }\end{array}$ & Immunoassay, ELISA & $\begin{array}{l}\text { TPA, B2M, Ki-67 } \\
\text { (MIB-1), CA 19-9, ER, } \\
\text { PR, and cytochrome } \\
\text { P450 2D6 genotype }\end{array}$ & $\begin{array}{l}\text { Immunoassay, } \\
\text { PCR-based assay for } \\
\text { cytochrome P450 }\end{array}$ \\
\hline & HER2* & $\begin{array}{l}\text { Immunoassay, fluorescence in } \\
\text { situ hybridization (FISH) }\end{array}$ & & \\
\hline $\begin{array}{l}\text { Breast cancer, } \\
\text { hereditary }\end{array}$ & BRCA1, BRCA2 & $\begin{array}{l}\text { DNA sequence analysis, } \\
\text { RT-PCR, and post-PCR curve } \\
\text { melting analysis }\end{array}$ & $\begin{array}{l}\text { The same as for } \\
\text { sporadic breast cancer } \\
\text { for monitoring }\end{array}$ & Immunoassay \\
\hline Prostate cancer & PSA, PAP & Immunoassay, ELISA & CEA, TPA & Immunoassay \\
\hline $\begin{array}{l}\text { Gastric cancer, } \\
\text { sporadic }\end{array}$ & $\begin{array}{l}\text { CA 19-9, CA 125, and CEA } \\
\text { HER2* }\end{array}$ & $\begin{array}{l}\text { Immunoassay, ELISA } \\
\text { Immunoassay, fluorescence in } \\
\text { situ hybridization (FISH) }\end{array}$ & $\begin{array}{l}\text { TPA, ferritin, and } \\
\text { gastrin }\end{array}$ & Immunoassay \\
\hline \multirow[t]{2}{*}{$\begin{array}{l}\text { Colorectal cancer, } \\
\text { hereditary }\end{array}$} & $\begin{array}{l}\text { MSI testing (BAT25, BAT26, } \\
\text { NR-21, NR-24, and } \\
\text { MONO-27), APC, AXIN2, } \\
\text { BMPR1A, CDH1, CHEK2, } \\
\text { MLH1, MLH3, MSH2, MSH6, } \\
\text { MYH/MutYH), TP53, PTEN, } \\
\text { PMS2, SCG5/GREM1, } \\
\text { SMAD4, and STK11 }\end{array}$ & $\begin{array}{l}\text { PCR-based test, IHC, DNA } \\
\text { sequence analysis, long-range } \\
\text { PCR, RT-PCR and post-PCR } \\
\text { curve melting analysis, } \\
\text { multiplex ligation probe } \\
\text { amplification (MLPA), and } \\
\text { array comparative genomic } \\
\text { hybridization (aCGH) }\end{array}$ & \multirow[t]{2}{*}{$\begin{array}{l}\text { The same as for } \\
\text { sporadic colon cancer } \\
\text { for monitoring }\end{array}$} & \multirow[t]{2}{*}{ Immunoassay } \\
\hline & $\begin{array}{l}\text { BRAF, MLH1 promoter } \\
\text { methylation }\end{array}$ & PCR-based test & & \\
\hline $\begin{array}{l}\text { Gastric cancer, } \\
\text { sporadic }\end{array}$ & $\begin{array}{l}\text { CA 19-9, CA 125, and CEA } \\
\text { HER2 }^{*}\end{array}$ & $\begin{array}{l}\text { Immunoassay, fluorescence in } \\
\text { situ hybridization (FISH) }\end{array}$ & $\begin{array}{l}\text { TPA, ferritin, and } \\
\text { gastrin }\end{array}$ & Immunoassay \\
\hline $\begin{array}{l}\text { Gastric cancer, } \\
\text { hereditary }\end{array}$ & CHD1 & $\begin{array}{l}\text { DNA sequence analysis, } \\
\text { RT-PCR, and post-PCR curve } \\
\text { melting analysis }\end{array}$ & $\begin{array}{l}\text { The same as for } \\
\text { sporadic gastric } \\
\text { cancer for monitoring }\end{array}$ & \\
\hline Oral cancer & SCC, CEA & Immunoassay & CA 19-9 & Immunoassay \\
\hline \multirow[b]{2}{*}{ Glioma } & MGMT promoter methylation & Methylation specific PCR & - & - \\
\hline & IDH1, IDH2 & $\begin{array}{l}\text { DNA sequence analysis, } \\
\text { RT-PCR, and post-PCR curve } \\
\text { melting analysis }\end{array}$ & - & - \\
\hline
\end{tabular}

*FISH using labeled DNA probes to the pericentromeric region of chromosome 17 and to the HER2 locus is superior to Southern, Northern, and Western blots and immunohistochemical analyses. Usually performed on tissue, however, blood tests can be ordered. (Note: individual laboratories may use different or other biomarkers and tests.)

the progress of the disease and the effects of therapeutic interventions or for estimating cancer risk in individuals with family history of hereditary types of cancers. Protein biomarkers are expected to be reliable predictors of the disease state and clinical outcome, since they probably most accurately reflect the pathogenic phenotype as they are the endpoint of biological processes [6]. However, more highthroughput genetic methods were recently introduced in clinical laboratories than advanced proteomic methods. For example, several gene expression PCR-based or microarraybased tests have been tested for use in clinics and validated in clinical trials, among them MammaPrint, BluePrint, and 
TargetPrint (Agendia Inc., Amsterdam, The Netherlands) for breast cancer, ColoPrint (Agendia Inc., Amsterdam, The Netherlands), TheraPrint (Agendia Inc., Amsterdam, The Netherlands), and Oncotype DX assay for breast, colon, and prostate cancer (Genomic Health, Inc., Redwood City, CA), Prolaris (Myriad Genetic Laboratories, Salt Lake City, UT) for prostate cancer, ColoGuideEx (Inven2, Oslo, Norway), and ColoGuidePro (Inven2, Oslo, Norway), and ColDX (ALMAC GROUP LTD, Craigavon, UK) for colorectal cancer [717]. Studies indicate that these tests could be cost-effective; however, the health insurance systems mostly do not cover their high costs. One of the main problems concerning genetic analyses of gene expression, gene mutations, epigenetic changes, and alterations of miRNA is that only in few cases the functional consequences of gene alterations were resolved. Functional assays, which determine the effect of gene alterations, are immensely complex to design and hard to perform in heterogeneous environment, such as human tissues. Considering that, comprehensive analyses of human proteome from clinical samples, such as serum or plasma, urine, spinal fluid, and tissues, are conducted and publicly available databases as well as bioinformatics analyses relevant to cancer proteomic studies have been recently developed and established [18-21]. Information collected in these large databases enables integration of transcriptomic, metabolomics, and proteomic profiles, which could ultimately contribute to identifying molecular features associated with cancers [19]. The interrogation of data on aberrant posttranslational modifications of proteins could reveal proteins, whose genetic information is intact, but pathogenic alterations render these proteins either nonfunctional, more stable, or more prone to degradation, or they could even obtain the ability to form new interactions with other cellular molecules such as proteins, nucleic acids, lipids, and cofactors, which are not their normal binding partners [4]. These modifications could also be of interest in developing new therapeutic approaches, since they could be reversible depending on the nature of the modification.

Despite remarkable innovations in proteomic methods and technologies in the last years, the integration of new proteomic technologies in clinical laboratories is slow due to the costs associated with acquisition of new instruments, evaluation of biomarker specificity and sensitivity, and obtaining information on clinical validity of biomarkers in large populations. This process is further complicated by the need for training technical and highly educated personnel in novel techniques and interpretation of obtained complex results [22-24]. Implementation of new instruments and methods also requires the establishment of appropriate laboratory reference systems in order to (1) ensure accuracy and reliability of diagnostic measurements; (2) provide quality control standards and standard laboratory procedures; and (3) provide monitoring and quality control assessment of laboratories. Furthermore, even though new high-throughput protein techniques produce large quantities of biological information, very few of the discovered protein biomarkers show the level of specificity and sensitivity necessary for use in clinical setting [22, 25-27].
Deciphering the clinical relevance of candidate proteins or protein profiles and introduction of new protein biomarkers into clinical setting is further complicated by the vast dynamic range of proteins and their normal isoforms, new isoforms associated with the particular type of cancer, aberrant processing into mature forms, anomalous chemical modifications of proteins, formation of immunocomplexes or complexes with other molecules, and heterogeneity of the disease [28]. Certain posttranslational modifications (e.g., phosphorylation, methylation, glycosylation, S-nitrosylation, $\mathrm{N}$-acetylation, lipidation, and proteolysis), which in healthy cells function as a key mechanism to increase proteome diversity, have been found to be altered in tumour cells, rendering nonfunctional proteins or modifying the target locations of the particular protein, and these changes could also be of importance in clinical diagnosis $[4,19,29]$. However, although sensitive proteomic methods have been developed for detecting these changes, translating the diagnostic significance of modified human proteomes in clinical samples is immensely complex [19]. Additionally, modern indepth analyses revealed evidence of evolutionary dynamics and selective pressures that govern tumour initiation and progression and promote cancer subclonal spatial and temporal heterogeneity [30, 31]. Cancer molecular heterogeneity can be observed on several levels: (1) genetic heterogeneitycopy number variations, point mutations, and different levels of gene expression; (2) heterogeneity in the germline background, which promotes generation of different aberrations in tumour cells and surrounding tumour stroma in individual patients; (3) epigenetic heterogeneity; and (4) phenotypic heterogeneity [30]. These inter- and intratumour heterogeneities add an additional level of complexity. Consequently, the researchers and healthcare personnel meet difficulties in interpreting the results and it is next to impossible to expect that two or more cancer patients could have the same alterations on the protein level.

In this review we first focus on proteomic approaches used in the discovery and validation of new cancer biomarkers. Additionally, we discuss the utility of these methods in research and identification of novel protein biomarkers and in translation of discovered biomarkers into clinical practice. Finally, we review promising biomarkers for most common solid tumours.

\section{Proteomic Biomarkers in Solid Tumours}

The set of proteins encoded by the genome comprises the proteome [32]. It is now well known that the proteome is dynamic and it changes in response to, for example, the physiological status of the organism. The field that encompasses studying such sets is called proteomics. Nonscientific PubMed inquiry finds first review papers using this term dating to 1998. By today, next-generation proteomics has evolved analogous to next-generation sequencing [33]. Modern proteomic technologies enable characterisation of almost complete proteomes and allow a much more in-depth view into biological and pathogenic processes.

Proteomics can be divided into two categories: bottomup or shotgun and top-down. In the first one, proteins are 
extracted from a sample, digested with an enzyme (trypsin), and potentially fractionated with liquid chromatography (LC). Peptides are then analysed via tandem mass spectrometry (MS/MS) and proteins in the original sample are identified [34]. In the second one, proteins are also isolated, processed to a limited degree, and, in the end, used for MS analysis intact [35].

A wide variety of separating techniques was developed over the years. Roughly, they can be divided into gel-based and non-gel-based. Two-dimensional gel electrophoresis (2DE) is one of the most widely used gel-based techniques. Dating back to 1970s, it has been the work horse of proteomics for quite some time [36]. As the name suggests, it is used to separate the proteins in two dimensions: according to their isoelectric point ( $\mathrm{pI}$ ) via isoelectric focusing (IEF) and according to their molecular weight via polyacrylamide gel electrophoresis (SDS-PAGE). Proteins, visible as spots on gels, are analysed with an appropriate computer software to identify differentially expressed specimens, which are then excised, enzymatically digested, and identified using MS or MS/MS [37]. Quite a lot of improvements have been made over time, both in the separation (e.g., the invention of immobilized $\mathrm{pH}$ gradients) and in the identification department (e.g., the development of MS instruments). A very important upgrade was the development of difference gel electrophoresis (2D-DIGE) [38]. It utilizes the advantage of fluorescent cyanine (Cy) dyes which are used to label the samples prior to any electrophoretic separation. One sample is labelled with $\mathrm{Cy} 3$, the other one with Cy5; they are then mixed together and separated in one single gel simultaneously. Scanning under different wavelengths results in two gel images representative of two different sample conditions or states, and at the same time it reduces gel-togel variations as the samples are separated on the same gel. Additional advantage adding to the reliability of this method is the use of an internal standard, comprised out of equal amounts of all the biological samples used in the experiment, labelled with a third dye, Cy2.

As already stated, MS can be used to complement a 2DE analysis [39]. Proteins can be identified by means of peptide mass fingerprinting after measuring the mass of peptides obtained by tryptic digestion, as is the case with the traditional matrix-assisted laser desorption/ionization timeof-flight MS (MALDI-TOF MS). Alternatively, peptide mass fingerprinting can be supplemented by sequencing of selected peptides by MS/MS, for example, with MALDI-TOF/TOF or electrospray ionisation MS/MS (ESI MS/MS).

Limitations of the gel-based approaches led to the development of gel-free methods, and MS started to become a core technology of proteomics [33]. In LC MS/MS, proteins are not separated prior digestion; however, peptides are fractionated via LC or other methods at least in one dimension due to sample complexity [39]. A combination of both approaches is also possible, to get a deeper insight into the proteome, such as using a regular SDS-PAGE prior to LC-MS/MS [39].

When using gel-free or combinatorial approaches, one has to choose how the quantitation will be done. Three main options are metabolic labelling, chemical labelling, or labelfree methods [40]. In metabolic labelling, such as stable isotope labelling by amino acids in cell culture (SILAC), the isotope-labelled substrate is introduced into every protein during cell growth and division [40, 41]. Chemical labelling is performed by labelling proteins or peptides after their isolation, as is the case with isotope-coded affinity tag (ICAT) and isobaric tags for relative and absolute quantitation (iTRAQ or TMT) [42-45]. Last but not least, label-free methods either directly utilize a peptide's response (intensity) in the mass spectrometer as a quantitative measure or infer quantity indirectly (e.g., spectral counting uses the number of peptideto-spectrum matches obtained for each protein) [46-52].

Protein microarrays, an approach analogous to DNA arrays, are designed to study protein functionalities in a high-throughput and flexible manner [53]. They are formed by immobilizing thousands of different proteins on a solid surface and can be roughly divided into analytical and functional microarrays. In the first approach, biomolecules with specific binding properties (e.g., antibodies) are printed on the surface to analyse the components of complex biological samples (e.g., serum and cell lysates) or to determine whether a sample contains a specific protein of interest. In the second approach, a large number of individually purified proteins are immobilized and mainly used to comprehensively query their biochemistry properties and activities. A proper surface and immobilization method, as well as signal detection method, which can take advantage of the label (i.e., a fluorescent dye) or be label-free, are important parameters to be considered when using a protein microarray.

Proteomics has facilitated cataloguing of protein profiles in different tissues and biological fluids [4]; however, identification of clinical biomarkers remains one of the most challenging applications [33]. Current biomarkers or biomarker candidates struggle with limited reliability and proper validation as well as with limited sensitivity and specificity [32].

There are several important factors to be considered in the search for a biomarker [54]. First of all, tissues as samples are not easily accessible, and, as they are composed of different cells, they are also very heterogeneous, an issue being addressed with labour intensive laser capture microdissection. However, it can be hardly expected that this approach could be integrated into clinical environment due to its complexity, time consumption, the need for educating the personnel, the costs associated with purchase of equipment, and last but not least, the availability of tissue samples. In clinical diagnosis there has always been a tendency to use most easily accessible specimens for diagnostic procedures, such as blood, saliva, urine, and faeces. On the other hand, regarding the proteomic methodologies, these fluidsalthough readily available-have the problem of dynamic complexity and are dependent on patient and environmental characteristics. Moreover, collecting the proper number of patients for biomarker validation can also pose a problem. And finally, it is becoming obvious that a single biomarker is not enough for accurate screening or diagnostic purposes; rather a panel of proteins will be necessary [24, 55-57].

2.1. Lung Cancer. Lung cancer has been the most common cancer worldwide for several decades and it has also been the 
most common cause of cancer-related death [58]. Cigarette and other tobacco products smoking is by far the leading cause of lung cancer [59]. Other established environmental risk factors include exposure to second hand tobacco smoke, occupational lung carcinogens (asbestos, nickel, chromium, and arsenic), radiation, and indoor and outdoor air pollution [59]. Older age, acquired lung disease, and infections (i.e., HIV) are also considered risk factors. Fruit consumption, to a lesser extent vegetable consumption, and physical activity are inversely associated with lung cancer risk. Another important factor is positive family history. Certain hereditary conditions, such as Li Fraumeni syndrome and, possibly, Bloom and Werner's syndrome, suggest a possible risk of lung cancer [60]. Mutated TP53 and RB1 are also associated with a higher risk, and other candidate genes include cholinergic receptor nicotinic alpha 3 (CHRNA3), cholinergic receptor nicotinic beta 4 (CHRNB4), and CHRNA5 [60], as well as EGFR [61, 62].

There are four major histological types of lung cancer: adenocarcinoma, which now occurs most frequently, squamous cell carcinoma, large-cell carcinoma, and small-cell carcinoma [63]. The high number of lung cancer deaths occurs mainly due to the high proportion of tumours diagnosed at an advanced stage $[64,65]$. Low-dose computer tomography shows promise for early detection; however, false-positive rates are of concern [63]. A validated, commercially available autoantibody assay Early CDT-Lung is also available; it detects autoantibodies against a panel of six tumour-related antigens (p53, NY-ESO-1, cancer-associated antigen (CAGE), GBU4-5, annexin 1, and SOX2) [66, 67]. Furthermore, protein biomarker detection could aid in the diagnostic process. Several potential biomarkers have already been identified (carcinoembryonic antigen (CEA), cytokeratin-19 fragment (CYFRA21-1), neuron specific enolase (NSE), and cancer antigen 125 (CA 125)) and are used in clinical setting; however, few have proven clinical utility, because they are not specific for lung cancer [68].

Intense research in this field gave rise to several review papers covering advancements in the protein biomarker research on several types of samples, such as tissue, blood, pleural effusion, exhaled breath condensate, and urine. In human lung cancer tissue, antioxidant enzyme AOE372, ATP synthase subunit d (ATP5D), 1,4-galactosyltransferase (B4GALT), cytosolic inorganic pyrophosphatase, glucoseregulated $\mathrm{Mr}$ 58,000 protein (GRP58), glutathione-Stransferase M4 (GSTM4), prolyl 4-hydroxylase b subunit (P4HB), triosephosphate isomerase (TPI), ubiquitin thiolesterase (UCHL1), isoforms of cytokeratin 7 (CK7), CK8, CK18, and CK19, $\alpha$-enolase (ENO1), pre-B cell-enhancing factor precursor, phosphoglycerate mutase 1 , fructose-bisphosphate aldolase $\mathrm{A}$, and guanine nucleotide-binding protein beta subunit-like protein; macrophage migration inhibitory factor (MIF), cyclophilin A (CYP-A), pyruvate kinase M1, manganese superoxide dismutase (MnSOD), peroxiredoxin, proteasome activator PA28, ubiquitin-ligase, prohibitin, Markush macrophage migration inhibition factor (MRP 14), IgE dependent histamine releasing factor, myosin regulatory light chain 2, a-casein; thymosin $\beta 4$ (TMSB4X), acyl-coA binding protein (ACBP), cystatin A (CSTA), cytochrome C, ubiquitin, and desubiquitin showed differential expression [68-71]. Several candidates were identified also in serum, for example, haptoglobin $(\mathrm{BH}) \beta$ chain, serum amyloid A (SAA), kallikrein (KLKB1), $\alpha_{1}$-antichymotrypsin (ACT), insulin-like growth factor-binding protein 3 (IGFBP3), prostaglandin D synthase (lipocalin-type, L-PGDS), aberrantly glycosylated apolipoprotein C3 (ApoC3), highly fucosylated forms of complement component 9 (C9), retinol binding protein (RBP4), $\alpha_{1}$-antitrypsin, squamous cell carcinoma antigen (SCCA), nectin-4, and pentraxin-3 [68, 71, 72]. In plasma, differential expression was observed for lung surfactant protein SFTBP, WAP four-disulfide core domain protein 2 (WFDC2), and angiopoietin-related protein 3 (ANGPTL3) [71]. Another sample source for potential biomarker candidates is pleural effusion, where Niemann-Pick disease type C2 protein (NPC2), periostin, multimerin 2, CD166, and lysosome-associated membrane glycoprotein-2 (LAMP2) were differentially expressed $[68,73]$. VEGF, bFGF, angiogenin (ANG), TNF- $\alpha$, and IL- 8 were altered in exhaled breath condensate [71], and HP, calprotectin (composed of S100A8 and 9), and zinc- $\alpha 2$-glycoprotein (AZGP1) in saliva [68]. Last but not least, urine analysis also enabled identification of CD59 glycoprotein, transthyretin, G(M2) activator protein (GM2AP), and Ig-free light chain as potential biomarker candidates [69].

Other recent efforts to discover protein biomarkers associated with lung adenocarcinoma include a 2D-DIGE and MALDI-TOF analysis, where Zhou et al. identified 22 differentially expressed proteins in tissue samples. Increased levels of tyrosyl-tRNA synthetase (TyrRS) and microtubuleactin cross-linking factorl (MACF-1) were confirmed using immunohistochemistry and serum ELISA [74]. Similar basic approach was utilized by Tan and colleagues who identified and verified via Western blot and immunohistochemistry isocitrate dehydrogenase 1 (IDH1) as a potential diagnostic and prognostic biomarker [75]. With iTRAQ, anterior gradient homolog 2 (AGR2) was identified as overexpressed in lung adenocarcinoma tissues [76]. An interesting approach was used by Gámez-Pozo et al.: after phosphopeptide enrichment they analysed paired non-small-cell lung cancer tissue samples by LC-MS/MS. PTRF/cavin-1 underexpression and migration inhibitory factor (MIF) overexpression were confirmed using Western blot and immunohistochemistry [77]. Differentially expressed proteins were determined also by reverse-phase protein array: among others, caveolin 1 and collagen type VI were underexpressed, while cyclin B1, ACC-pS79, CHK2, and IGFBP2 were overexpressed in lung cancer tissues [78]. The finding was validated with Western blot. Zeng and colleagues used laser-capture microdissected tissues and analysed them with iTRAQ [79]. Three proteins, GSTP1, heat shock protein beta-1 (HSP27), and creatine kinase brain-type (CKB), were validated using Western blot and immunohistochemistry, and the authors proposed them as potential biomarkers for early detection of lung squamous cell carcinoma. MALDI-TOF on bronchoscopic biopsy samples is another approach for potential biomarker identification. In this manner, calcyclin was identified as being under-expressed in small-cell lung cancer and verified with immunohistochemistry [80]. Immunohistochemistry 
was also used to determine differential expression of endothelial cell protein $C$ receptor (EPCR), as well as increased metalloproteinase-2 (MMP-2) and reduced $\beta$-catenin levels, which may play important roles in initiation, progression, and metastasis of non-small-cell lung cancer [81, 82]. In sera of patients with lung cancer, especially in those with squamous-cell carcinoma, cytokeratin 2G2 was elevated [83]. In another study, protein profiling using ProteinChip and MALDI-TOF revealed that fibrinogen alpha chain was elevated in the sera from patients with stage I squamous-cell carcinoma [84]. Serum activated protein kinase C (PKC $\alpha)$ was also proposed as probable biomarker applicable to lung cancer diagnosis [85]. Liu et al. performed LC-MS/MS on serum samples in order to identify proteins associated with non-small-cell lung cancer [86]. Immunohistochemical staining on a tissue microarray was then carried out for alpha1B-glycoprotein (A1BG), leucine-rich alpha-2-glycoprotein (LRG1), ubiquitin carboxyl-terminal hydrolase 1 (USP1), and mucin-5B as candidate biomarkers. Their levels were significantly elevated in lung cancer tissue. A1BG levels were also determined as significantly elevated with Western blot on sera samples. Another candidate for a cancer specific single marker capable of identifying early-stage lung cancer within at-risk groups without resort to invasive procedures is a variant form of the nuclear matrix-associated DNA replication factor Ciz1 [87]. Its clinical utility was inferred from Western blot on two independent larger sets of plasma samples. Bronchoalveolar lavage fluid is another sample type that could be used for candidate biomarker searching. Pastor et al. used it for 2DE and MS analysis of several groups of samples, including lung cancer group and control group. They identified seven differentially expressed proteins in the tumour versus control setting and confirmed increased AKR1B10 levels using Western blot [88].

2.2. Breast Cancer. Breast cancer is by far the most common cancer in women and second most common in both sexes [58]. It ranks as the fifth cause of death from cancer overall. Besides female gender and age, obesity, diet, and physical activity have been linked to breast cancer $[89,90]$. It is now known that hereditary breast cancer accounts for $5-10 \%$ of all cases. The first discovered susceptibility genes were BRCA1 and $B R C A 2$, but further studies revealed other genes such as TP53, PTEN, STK11, CHEK2, ATM, PALB2, BRIP1, and CASP8 [91]. To date, breast cancer risk assessment is largely restricted to testing for high-penetrance mutations by genetic methods.

Invasive breast cancers constitute a heterogeneous group of lesions. Most of them are adenocarcinomas and the most common types are ductal and lobular [90]. Mammography is the primary imaging modality for population-based breast cancer screening and early detection does decrease breast cancer mortality [92]. However, mammography remains an imperfect test, and it does not detect all breast cancer types.

Based on prognostic factors and hormone receptor status, as well as the extent of surgery performed, adjuvant treatment may be given that includes hormone manipulation and/or chemotherapy and local radiotherapy [90]. However, even with advances in surgical and adjuvant therapies for earlystage disease, most patients eventually experience disease progression or recurrence [91].

There is no molecular biomarker sufficiently powered for use in current clinical practice for breast cancer screening or early detection [93]. The mucin glycoproteins MUC-1 and cancer antigens CA 15-3 and CA 27-29 are the best characterized serum markers related to breast cancer, but they have not been recommended for diagnostic use due to low sensitivity [94]. New potential biomarkers are being sought and recently several review papers summarized some of the candidates found in tissues, blood, nipple aspirate fluid, ductal lavage, pleural effusion, fine-needle aspiration, or core needle biopsy $[93,95,96]$. In serum, isoform 1 of inter-alpha trypsin inhibitor heavy chain (ITIH4), fibronectin 1, CXCL9, apolipoproteins ApoA1, ApoA2, ApoC1, ApoC2, ApoC3, and ApoE, C3a des-arginine anaphylatoxin (C3adesArg), C3f, C4a, platelet factor 4 , haemoglobin $\alpha$-chain and $\beta$ chain, transferrin, epidermal growth factor receptor (EGFR), mammaglobin, afamin, $\alpha$-2-macroglobulin, ceruloplasmin, bradykinin, transthyretin, fibrinopeptide $\mathrm{A}$, and fibrinogen $\alpha$ showed differential expression $[93,96]$. Gross cystic disease fluid protein 15 (GCDFP-15), $\alpha 1$-acid glycoprotein (AAG), and basic fibroblast growth factor (bFGF) were differentially expressed in nipple aspirate fluid [93]. Identified and validated as differentially expressed in tissue samples were also ubiquitin, protein S100-A8, $\alpha$-B-crystalin, HER3, cathepsin $\mathrm{H}$ (CATH), heat shock protein beta-1 (Hsp27), protein S100-A6, and desmoglein-3 (DSG3) [95].

S100 proteins are a potentially promising group of biomarkers in cancer development and progression. A largescale proteomic screening using 2DE and MS for identification and Western blot for validation identified several S100 proteins (11 isoforms as 7 members) as overexpressed in breast cancer tissues [97]. Similar methodology was used to identify over-expression of calreticulin [98]. Using SDS-PAGE, LC-MS/MS, and Western blot protein disulfide isomerase A3 (PDIA3) was identified and validated as overexpressed in breast cancer tissue [99]. A-Kinase Anchor Protein 4 (AKAP4) was also determined as overexpressed in breast cancer tissues using immunohistochemistry and ELISA assay showed that anti-AKAP4 autoantibodies were elevated in sera of patients, making them a potential biomarker for early detection and diagnosis [100]. Metastasis-associated in colon cancer-1 (MACC1) was found overexpressed by Western blot and immunohistochemistry in breast cancer tissues [101]. Moreover, it was associated with survival and as such showed potential as a prognostic biomarker. Similarly, overexpression of lysosome-associated protein transmembrane 4 beta (LAPTM4B) was determined immunohistochemically, and it correlated with disease progression and poor prognosis [102]. Breast cancer tissues were also found displaying overexpression of $\gamma$-glutamyl hydrolase (GGH) and fatty acid amide hydrolase (FAAH) and underexpression of TAF5-like RNA polymerase II p300/CBP-associated factor (PCAF)associated factor $65 \mathrm{kDa}$ subunit 5L (TAF5L) [103]. Bone morphogenetic protein 6 (BMP6), on the other hand, was under-expressed in breast cancer tissues [104]. Its differential expression correlated with the oestrogen and progesterone 
receptor status, tumour grade, and enhanced proliferation. Underexpression was also determined for huntingtinassociated protein 1 (HAP1) [105]. Using sera as samples and multiple fractionation steps (protein depletion, lectin affinity fractionation, IEF separation, and LC-MS analysis), the following candidates were selected as breast cancerassociated proteins: thrombospondin-1 (TSP1) and 5 (TSP5), alpha-1B-glycoprotein (A1BG), serum amyloid P-component (SAP), and tenascin-X (TN-X) [106]. SAP and TSP5 were increased in breast cancer serum, A1BG showed a pI shift and a slight increase in total abundance in the cancer samples, TSP1 showed changes in glycan structure, and TN-X was both increased and showed glycan structure changes. The slight over-expression of the latter was also verified with ELISA. With 2DE, MS, Western blot, and ELISA inhibitor of apoptosis protein-like protein-2 (ILP-2) was determined and validated as overexpressed in sera of breast cancer patients [107]. Biotinidase (BTD) is another potential biomarker. Kang and colleagues identified it using ICAT and validated its underexpression with Western blot in plasma samples from breast cancer patients [108]. Another study using plasma showed that thrombospondin-1 (THBS1) and bromodomain and WD repeat-containing protein 3 (BRWD3) were overexpressed in breast cancer using mTRAQ and Western blot [109]. In a 2D-DIGE and Western blot experiment, Zhang et al. identified several differentially expressed proteins in saliva of breast cancer patients and healthy controls: carbonic anhydrase 6 (CA6) showed the most significant difference among four validated proteins [110]. An interesting approach was used by Bohm et al. They analysed tears of breast cancer patients and compared them to normal controls using SDSPAGE and MALDI-TOF/TOF [111]. They analysed over 20 differentially expressed proteins, such as C1Q1, ALDH3A, or TPI, but they require further validation.

2.3. Prostate Cancer. Prostate cancer is the second most frequently diagnosed cancer worldwide and the sixth leading cause of cancer death in men [56, 112]. A familial history of prostate cancer, increasing age, ethnicity, low testosterone levels, diet rich in fats, and $B R C A 1 / 2$ mutations can contribute to the development of this neoplasm [56, 113-115]. GWAS studies and large-scale population screening studies revealed several other susceptibility loci, which include genes HPCl, HPC10, HPC14, and TERT [116-119].

Prostate specific antigen (PSA) has been the mainstay for diagnosis and prognosis of prostate cancer in blood [120]. The routine use of PSA screening remains controversial, owing to its limited specificity and sensitivity. Its usefulness is limited because there can be other different reasons for elevated PSA levels, including routine rectal examination of prostate, benign prostate enlargement, inflammation, infection, age, race, and normal leaking of PSA in the circulation [120, 121]. One advantage of detecting PSA levels is that it is tissue specific, so a rise of its concentration in blood is fairly specific to a prostate problem. However, PSA fails to discriminate between aggressive tumours and low-risk ones and between malignant disease and other benign prostate conditions, and as such, overdetection and overtreatment represent critical consequences of PSA-based screening [122124]. For these reasons, it is imperative to understand the underlying molecular mechanisms leading to prostate cancer in order to identify more sensitive and specific biomarkers to enable more accurate diagnosis and prognosis $[56,120]$.

A number of proteomic studies using different MS approaches, immunohistochemistry, ELISA, RIA, and bioinformatic analyses attempted to identify screening/diagnostic (protein biomarkers used for the detection of cancer), prognostic (protein biomarkers, which are used to predict the course of the disease), and stratification (proteins that predict the response to treatment modalities) protein biomarkers in tumour tissues (extensively reviewed in $[56,125]$ ).

Ideally, however, for early diagnosis of the malignant disease, the detection of prostate cancer biomarkers should be based on screening procedures in serum, plasma, urine, prostatic secretion, or seminal plasma, since collecting these biological fluids is minimally invasive and fast [56]. Rehman and colleagues profiled pooled serum samples from 4 carefully selected groups of patients representing the various stages of prostate cancer development and progression using a 4-plex iTRAQ approach [126]. They identified 75 proteins, which belonged to diverse biological pathways such as protein metabolism and modification; blood clotting; proteolysis; immunity and defence; complement mediated immunity; and blood circulation and gas exchange. Interestingly, some of these have previously been reported as candidate prostate cancer biomarkers, including CRP, alpha2-macroglobulin, ceruloplasmin, zinc-alpha-2-glycoprotein, beta-2-microglobulin, and fibronectin [126-131]. Theodorescu et al. speculated that relevant quantities of prostate cancer biomarkers could be present in prostatic fluid, which is preferentially secreted in void urine [132]. Using CE-MS they identified a panel of 12 urinary polypeptide markers and later validated these markers in a blinded prospective multicentre study on a larger set of patients. Prostate cancer was detected with $89 \%$ sensitivity and $51 \%$ specificity. Including age and percent free PSA to the proteomic signatures resulted in $91 \%$ sensitivity and $69 \%$ specificity. Polypeptide markers were identified by sequencing and several different proteins were identified, including sodium/potassiumtransporting ATPase $\gamma$, collagen $\alpha-1$ (III), collagen $\alpha-1$ (I), psoriasis susceptibility 1 candidate gene 2 protein (also called SPR1), fragments of glioma tumour suppressor candidate region gene 1, hepatocellular carcinoma associated protein TB6, histone H2B, osteopontin, polymeric Ig receptor, transmembrane secretory component, prostatic acid phosphatase, prostate specific antigen, fibrinogen alpha chain precursor, and semenogelin 1. Interestingly, the majority of marker candidates in this study were determined as downregulated in patients with prostate cancer compared to patients with negative biopsies. Similar study was later performed in an independent cohort of 184 patients in Germany [133]. They confirmed the utility and applicability of the test for routine clinical practice, obtaining a high negative predictive value of $92 \%$. A negative UPA-PC test result in patients with slightly to moderately increased total PSA could initiate a specific monitoring programme for patients, 
including regular PSA examinations rather than examination of prostate biopsy [133]. Overall the test showed a sensitivity of $86 \%$ and specificity of $59 \%$. Quantitative proteomic analysis using collagenase digestion of tissue samples followed by glycopeptide-capture MS/MS revealed 5-fold overexpression of CD90 glycopeptide in cancer versus noncancer tissues. Furthermore, three differently glycosylated forms of CD90 were observed. CD90 (cluster of differentiation 90), also known as Thy-1 (thymocyte differentiation antigen 1), is a N-glycosylated cell surface protein first identified in the thymus as a T-cell maturation and differentiation marker. Immunohistochemical analysis of prostate cancer samples showed distinct and differential overexpression of CD90 in cancer-associated stroma compared with noncancer tissue stroma. Since CD90 might be released from cells, the authors then attempted to identify CD90 in void urine samples and detected CD90 peptides by ICAT in the preprostatectomy samples but not in the postprostectomy samples, confirming that CD90 is secreted by prostate cancer stromal tissue. PEDF (pigment epithelium-derived factor) and zinc-alpha2glycoprotein were identified using 2D-DIGE followed by LCMS/MS in a small sample of patients with different grades of prostate cancer [134]. Both proteins were extensively validated in a larger independent cohort of patients, and the results indicated that PEDF is an accurate predictor of early stage prostate cancer. PEDF was also studied in patients with high-grade prostatic intraepithelial neoplasia, which is most likely precursor of prostate cancer, and patients with prostate cancer, revealing that PEDF could be significant predictor of prostate neoplasia. All of the patients with prostate cancer had weak expression of PEDF, 2 patients with high-grade prostatic intraepithelial neoplasia showed strong PEDF expression, 3 patients had moderate expression, and 6 patients with highgrade prostatic intraepithelial neoplasia weakly expressed PEDF. The ten-month follow-up study demonstrated that 2 of 6 patients with high-grade prostatic intraepithelial neoplasia with weakly expressed PEDF subsequently developed prostate cancer. Several other studies identified different protein biomarkers in sera or urine, including afamin, CXCL16, spondin 2, pentraxin 3, engrailed-2, fibronectin 1, eukaryotic translation elongation factor 1 , interleukin-6, ceruloplasmin, and complement protein $\mathrm{C} 5$; however, further studies are needed to confirm their role in prostate carcinogenesis and their usefulness as clinical biomarkers [126, 130, 135-137].

2.4. Colorectal Cancer. Colorectal cancer is the second or third most commonly diagnosed cancer in men and women in the world, respectively. The major disease pathways include the aneuploidy or chromosomal instability pathway involving mutations in APC, DCC, TP53, KRAS, SMAD2, and $S M A D 4$ and the $\mathrm{CpG}$ island methylator phenotype (CIMP) pathway, which is the second major pathway leading to the development of sporadic colorectal cancers and includes sporadic microsatellite instability (MSI) high cancers. The third pathway, the MSI pathway, is the consequence of germline mutation in a DNA mismatch repair (MMR) genes (i.e., MLH1, MSH2, MSH6, and PMS2) [138, 139]. The hereditary deficiency in MMR genes is the cause for the most common form of hereditary colorectal cancer, Lynch syndrome (previously known as hereditary nonpolyposis colorectal cancer), accounting for $1 \%$ to $3 \%$ of all colorectal tumours [140]. MUTYH-associated polyposis (MAP) is an autosomal recessive hereditary syndrome that predisposes individuals to attenuated adenomatous polyposis and colorectal cancer [141-143]. It is caused by biallelic germline mutations in the Mut Y human homologue $(M U T Y H)$ gene, encoding A/G specific adenine DNA glycosylase excision repair protein [143]. Another inherited syndrome, which follows autosomal dominant inheritance, is familial adenomatous polyposis (FAP) and is characterized by germline mutations in APC gene $[144,145]$. With regard to risk stratification, the most robust identification strategy to date is detecting germline mutations in genes that cause these and other hereditary colon cancer syndromes (e.g., APC mutations in FAP and MSI and mutations in MMR genes in Lynch syndrome, MUTYH biallelic mutations in MAP, and BMPR1A in juvenile polyposis, etc.) [146]. Clinical diagnosis, which confirms the start of the disease in an individual with known hereditary mutation, is based on different surveillance schemes, which most commonly involve endoscopic imaging, such as colonoscopy or flexible sigmoidoscopy. The start and intervals of these diagnostic procedures should be based on the family history and type of mutation, as well as individual preferences (NCCN Guidelines, Colorectal Cancer Screening). In some cases, there is no known family history of the inherited syndrome; diagnosis is then based on certain histopathological characteristics of polyps and/or tumours, followed by confirmation of inherited genetic factors using genetic testing for mutations in MMR genes, MUTYH, and $A P C$. However, hereditary syndromes account for a small percentage of colorectal cancers. About $75 \%$ of patients with colorectal cancer have sporadic disease with no apparent evidence of having inherited the disorder (NCI, Genetics of Colorectal Cancer (PDQ), 2013). The remaining 25\% of cases have a family history of the disease; however, it has been estimated that well characterized genetic mutations in highly penetrant genes account for only $5 \%$ to $6 \%$ of colorectal cancer cases overall. It is likely that less penetrant inherited susceptibility genes contribute to the development of the remaining cases of familial colorectal cancer in conjunction with environmental risk factors [147]. It is well established that early screening for polyps in family members of patients with characterized mutations in MMR (Lynch syndrome), APC (FAP), or MUTYH (MAP) genes is beneficial in improving detection of malignant changes and reduces mortality. However, as sporadic colorectal cancer occurs much more frequently, it would be beneficial to establish reliable screening methods for early detection. Several developed countries successfully employ national programme screening for early detection of precancerous lesions and cancer of the colon and rectum in men and women between 50 and 69 years with the aim to reduce morbidity and mortality due to these cancers [148-150]. The most common strategy is based on using a faecal-based self-sampling kit for faecal occult blood test (FOBT), followed by colonoscopy or sigmoidoscopy, if the FOBT was positive $[150,151]$. Two FOBT test are available, 
guaiac-based, which detects haemoglobin enzymatically, and immunochemical-based faecal immunochemical test (FIT), which detects human globin within haemoglobin. However, main limitations of these noninvasive tests are low specificity and sensitivity $[152,153]$. Furthermore, enzymatic FOBT is susceptible to nonhuman heme from dietary sources and blood from upper gastrointestinal tract [153]. Although the examination by colonoscopy is expensive and inconvenient, it is still the most used type of colorectal cancer detection $[153,154]$.

Discovery of more suitable and noninvasive molecular biomarkers and development of reliable biomarker assays are long and complex processes [154]. Ideally, the biomarkers for early detection of colon malignancies should be shed by tumour cells and released into either bloodstream or intestinal lumen, so they could be detected in blood or faeces [155]. Several studies and clinical trials addressed identification and validation of molecular biomarkers in tumour tissues; however, tissue samples are not always available, and the quality of tissue storage varies between laboratories, therefore making validation of these markers difficult [156].

CEA, carbohydrate antigen CA 19-9, and tissue inhibitor metalloproteinase type I are the best characterized serum prognostic biomarkers to date; however, none of them is specific for colorectal cancer [153, 154, 157-159]. Five-serummarker panel, including spondin-2, DcR3, Trail-R2, Reg IV, and MICl, six SELDI peaks, corresponding to ApoCl, C3a-desArg, $\alpha_{1}$-antitrypsin, and transferrin, PSME3, NNMT, CRMP-2, defensins (HNP 1-3), MIF, macrophage colonystimulating factor (M-CSF), tumour pyruvate kinase isoenzyme type M2 (M2-PK), prolactin, CCSA-2, -3 -4, metalloproteinases MMP-9 and MMP-7, and laminin have been included in preclinical validation and assay development $[153,160-162]$. Unfortunately, none of the markers showed adequate specificity and sensitivity, although, M-CSF, for example, could be used for lymph node metastasis prediction [163]. Furthermore, the biological relevance of most of these biomarkers to colorectal cancer remains unclear and raises the question whether their appearance in serum could be due to secondary effects of cancer rather than specific to tumour tissues due to secretion or leakage [155]. Several other studies have assessed the predictive and prognostic significance of serum proteome from patients with colorectal cancer using MS-based proteomic methods with varying results $[152,164-169]$. Some of these studies identified only peptide/protein peaks which were differentially expressed between colorectal cancer patients and healthy controls without further identification of proteins. However, these serum proteome profiles could potentially serve as a diagnostic method for colorectal cancer screening after validation on larger populations. Klein-Scory et al. researched another approach to identify specific signature of colorectal cells [170] Using 2DE, serological screening on PDVF membranes with sera from colorectal patients and healthy controls, followed by identification of selected proteins with MALDI-MS and/or by LC-MS/MS and Western blot validation they analysed the extracellular proteome of five colorectal cancer cell lines. Aiming to discover specific patterns in the secretome (extracellular proteome), which presumably triggers immune response in cancer patients and is believed to be enriched in biomarkers due to the humoral immune response, they identified two novel biomarkers, Glod4, a glyoxalase-domain containing protein, and a C-terminal fragment of agrin, a heparansulfate proteoglycan resident in basement membranes, and several other differentially expressed proteins or protein fragments, such as PGAM1, syntenin, aldolase C, LMAN2, VIP36, and Rad23b. Another interesting approach involves detecting mutant tumour proteins in the serum or tissues of colorectal cancer patients using immunoprecipitation or gel-based methods for enrichment of tumour specific biomarkers, followed by LC-MS/MS and targeted mass spectrometry approach, such as selected reaction monitoring (SRM) MS or multiple reaction monitoring (MRM) MS [171-174]. Ruppen-Canas et al. and Wang et al. used immuno-LC-MS-SRM approach to detect wild-type and mutant RAS proteins in colorectal and pancreatic cancer tissues, benign skin tumours, and pancreatic cyst fluid [173, 174]. One of the advantages of this approach is that numerous independent proteins could be assessed simultaneously in a relatively small amount of clinical samples. Identification of mutant proteins in clinical samples could potentially serve as drug-related biomarkers and aid in selection of appropriate chemotherapy strategies. Lumachi et al. used simple multianalyte immunoassay for measurement of five markers, CEA, CA 19-9 and 72-4, CYFRA 21-1, and osteopontin, comparing their expressions in patients with colorectal cancer and age- and sex-matched patients suffering from confirmed benign colorectal diseases (controls) [175]. Single marker measurements showed, as expected, low specificity and sensitivity; however, simultaneous measurements of all five markers achieved $74.1 \%$ sensitivity and $94.3 \%$ specificity in patients with colorectal cancer. The authors speculated that this panel could have enough diagnostic accuracy to be evaluated as a tool for screening for colorectal cancer.

Recent methodological advances have allowed the proteome identification of faecal-borne biomarkers, thus providing an opportunity to establish other noninvasive diagnostic methods for detecting colorectal cancer [155]. Karl and colleagues evaluated expression of S100A12 and TIMP-1 using ELISA, which showed comparable diagnostic performance with the established immune-FOBT [176]. The combination of S100A12, immune-FOBT, and TIMP-1 reached sensitivity greater than $80 \%$ at a high specificity (98\%), giving noninvasive colorectal cancer screening in stool a new perspective. M2-PK was also extensively evaluated as potential secreted biomarker in stool samples by several groups of researchers with varying results [177-182]. The limited specificity of many ELISAs, and in many cases limited antibody availability for assay development and validation, and low specificity and sensitivity of established assays, coupled with recent advances in MS technology, are stimulating further research in order to obtain reliable protein or peptide profiles from faeces [183]. Ang et al. validated 60 potential secreted biomarkers selected from the literature using SDS-PAGE separation followed by MRM analysis on high pressure LC-MS system (HPLCMS) [183]. Myeloperoxidase, hemoglobin, protein S100A9, filamin A, and L-plastin were confirmed to be present at significant levels only in the feces of the colorectal cancer 
patients. In another small-scale screening Ang and colleagues identified nine proteins, a-1-antityrpsin, a-1-acid glycoprotein, complement C3, fibrinogen, haptoglobin, hemoglobin $\alpha$, hemoglobin $\beta$, myeloblastin, and transferrin, which were detected only in the samples from patients with colorectal cancer [184]. Initially, they used discovery approach to select peptides for analytical MRM assay. They obtained a peptide library containing 108 proteins present in faeces of both cancer patients and nondiseased patients using three alternative prefractionation strategies (SDS PAGE, reverse phase high pressure LC (RP-HPLC), and size exclusion chromatography) followed by RP-HPLC MS/MS identification. 40 proteins were selected for multiplex screening by MRMbased assay on a set of colorectal patients and healthy volunteers. Although the method is complex, the protein panel, if evaluated on a larger cohort of samples, could be reengineered to antibody-based assay, compatible with current clinical analysers [184]. Bosch et al. [185] performed a pilot study by gel electrophoresis separation and LC-MS/MS in stool samples from colorectal cancer patients and patients with negative colonoscopy. They identified 134 significantly overexpressed proteins in samples of colorectal patients.

2.5. Gastric Cancer. Gastric cancer is the fourth most common malignancy and the second leading cause of cancer death worldwide [58]. It is more common in developing countries. Environmental and behavioural risk factors are very important: salt intake, tobacco use, and alcohol consumption intake have a negative impact, while fruit and vegetable intake and increased use of refrigeration of food storage (rather than salting, pickling, and smoking) act protective [186]. From infectious causes, Helicobacter pylori is recognized as WHO class I carcinogen, and Epstein-Barr virus has also been associated with gastric cancer. There are also some known hereditary components [186]. Hereditary diffuse gastric cancer stands for early onset of diffuse gastric adenocarcinoma, autosomal dominant disease penetration, and an increased risk of lobular breast cancer and signet ring cell colon cancer. It is caused by a germline mutation in CDH1, a gene coding for E-cadherin, a calcium dependent cell dependent cell adhesion protein responsible for cellcell interaction and cell polarity. It is possible that the lack of immunohistochemically detectable E-cadherin expression may be a useful diagnostic adjunct [187]. Prophylactic gastrectomy in such individuals can be performed. There are also other hereditary conditions associated to gastric cancer, such as Lynch syndrome, FAP, and Li Fraumeni syndrome [186]. The most common form of gastric cancer is gastric adenocarcinoma, which has historically been divided into diffuse and intestinal type, but there are also other classifications, that is, according to the location $[186,188]$.

Radical surgery is currently the only possible cure for gastric cancer, invading the muscular layer; however, the majority of patients are diagnosed at an advanced stage, where a systemic spread of the tumour cells has to be anticipated [189]. Finding early diagnosis biomarkers is therefore of utmost importance.

Unfortunately, early gastric cancer is asymptomatic. Current clinical diagnostic biomarkers, such as CEA, CA 19-9, and CA 72-4, are not specific and sensitive enough [190]. Proteomic approaches facilitated the search of new potential biomarkers and gave quite some candidates up to now. Lin and colleagues summarized some of these studies performed on different clinical samples, such as blood, gastric fluid and tissues, as well as cell lines and animal models [190]. Complement factor I precursor (CFI), C9, IPO-38, inter- $\alpha$ trypsin inhibitor H3 (ITIH3), SLe, ApoC1, ApoC3, thrombin light chain A, and MIF were detected and validated as differentially expressed in blood specimens. Pepsinogen $\mathrm{C}$ (PGC), pepsin A, $\alpha$-defensin, $\alpha_{1}$-antitrypsin precursor and $\alpha_{1}$-antitryspin, gastrokine-1 (GKN1), trefoil factor 1 (TFF1), and pepsinogen II were identified and confirmed as differentially expressed in gastric fluid. The majority of potential biomarkers were determined in paired tissue samples. Serum-binding protein 1, ENO1, glucose regulated proteins GRP78 and GRP94, cyclosporine A-binding-protein (PPIA), peroxiredoxin-1 (PRDX1), phosphatase and tensin homolog (PTEN), MAWD-binding protein; mitotic arrest-deficient 1like 1 (MAD1L1), HSP27, protein CYR61, chloride intracellular channel 1 (CLIC1), cathepsin B, GKN1, ATP-dependent RNA helicase DDX39, lactate dehydrogenase A (LDHA), pyruvate dehydrogenase $\mathrm{B}$ (PDHB), hypoxia-inducible factor (HIF), cysteine-rich intestinal protein 1 (CRIP1), $\alpha$-defensin1, $\alpha$-defensin-2, proteins S100A8, S100A6 and S100A9, PGC, human neutrophil peptides 1-3 (HNPs 1-3) and macrophage migration inhibitory factor, galectin-2, ApoA1, S100P, laminin gamma 2 chain monomer, human epidermal growth factor receptor 2 (HER2), glycolipid and GM2 were detected and validated as differentially expressed in tissue samples.

Our laboratory is also trying to find potential biomarkers for gastric cancer: using 2DE and MS, 39S ribosomal protein L12 (mitochondrial precursor; MRPL12), among others, was determined as under-expressed and the finding was validated with immunoblotting [191]. Analyzing paraffinembedded samples, Sousa and colleagues found a variety of proteins overexpressed in metaplasia and intestinal type cancer: lactotransferrin (LTF) and deleted in malignant brain tumor 1 (DMBT1) were validated as metaplasia biomarkers as well as potential prognostic gastric cancer biomarkers [192]. Leucine-rich repeat-containing $G$ protein-coupled receptor 5 (LGR5) was also determined as overexpressed in gastric cancer by immune-staining and proposed as a possible prognostic biomarker [193], and similar findings were confirmed for kallikrein 12 (KLK12) [194], and plasma membrane protein solute carrier family 3 member 2 isoform b (SLC3A2) [195]. Using plasma samples, signal peptide-CUB-EGF domaincontaining protein 1 (SCUBE 1) was found elevated in patients with gastric cancer [196]. Another approach used a panel of potential serum biomarkers; epidermal growth factor receptor (EGFR), pro-ApoA1, ApoA1, transthyretin (TTR), regulated upon activation, normally T-expressed and presumably secreted (RANTES), D-dimer, vitronectin (VN), interleukin-6 (IL-6), $\alpha$-2 macroglobulin, C-reactive protein (CRP), and plasminogen activator inhibitor-1 (PAI-I) were selected as classifiers in the two algorithms that accurately differentiated between the majority of gastric adenocarcinoma and control serum samples [197]. Taking the advantages of 
glycoproteomics into account, Uen and colleagues found several Con A bound glycoproteins in plasma of gastric cancer patients [198]. After validation on tumour and nontumour tissue samples, leucine-rich alpha-2-glycoprotein (LRG1) and inter-alpha-trypsin inhibitor heavy chain H13 (ITIH3) were determined as being overexpressed in tumour tissues; however, their practical use in the clinical environment is questioned. Urine is another easily accessible fluid and a possible biomarker source; endothelial lipase (EL) was found significantly decreased in urine samples of gastric cancer patients [199]. Interestingly, it was not as distinctive in tissue and serum samples.

2.6. Protein Biomarkers in Detection of Other Cancers. Primary brain tumours are rare in adults, but not in children [200]. Neuroepithelial tumours are the most common, and the WHO subdivides them into a variety of histologic tumour types, such as glial (astrocytomas, oligodendrogliomas, and ependymomas), neuronal, mixed glialneuronal, embryonal, pineal, and choroid plexus derived. Astrocytomas are a morphologically heterogeneous group of neoplasms and defined as tumours with predominantly astrocytic differentiation. Diffusely infiltrating astrocytic tumours are the most common primary neoplasms in adults and constitute more than $60 \%$ of all brain tumours. Glioblastomas (WHO grade IV) are the most malignant tumours within this spectrum and account for approximately $12 \%$ to $15 \%$ of all intracranial neoplasms and up to $60 \%$ of all astrocytic tumours. Despite distinct progress in surgical resection, radiation, and chemotherapy, the prognosis of patients with glioblastoma multiforme is still very poor: 5 -year survival rate is approximately $5 \%$ [201, 202]. Up to now, no established clinical cerebrospinal fluid or serum markers exist and histopathological analysis of the tumour tissue is mandatory for a definite diagnosis [202]. Proteomics enabled the identification of several promising candidates from tissue, blood, cerebrospinal fluid, cell lines or even animal models using 2DE and MS, SELDI-TOF, protein microarrays, LC-MS/MS, ELISA, and so forth [203205]. In our laboratory we took an interesting approach of finding new potential glioblastoma biomarkers using llama heavy-chain antibodies (project GLIOMA). Camelids have two types of antibodies: regular and the so-called heavy-chain antibodies, which lack a light chain and as a consequence their antigen-binding site is reduced to one single domain (VHH or nanobody) [206]. Their sequence and structure adaptation enables them to have additional diversity in their antigen-binding repertoire, which could enable us to find either novel or altered proteins as biomarker candidates.

Oral cancer accounts for 2-3\% of all malignancies and occurs most commonly in the form of squamous cell carcinoma $[207,208]$. The five-year survival rate of patients is about $40 \%$ and has not improved significantly in recent decades, despite advances in surgery, radiotherapy, and chemotherapy $[207,209]$. There are currently no effective methods to screen for oral cancer [207]. Saliva represents an easily obtainable clinical sample for biomarker detection; however, its protein complexity makes identification of potential biomarkers challenging [208]. One of the advantages of saliva is also the assumption that proteins and/or cells are almost certainly shed or secreted into it from oral lesions $[208,210]$. Proteomic approaches based on ELISA identified potential saliva biomarkers in patients with oral cancer, such as underrepresentation of secretory immunoglobulin A, 8-oxoguanine DNA glycosylase, phosphorylated-Src, and mammary serine protease inhibitor (Maspin) and overrepresentation of insulin growth factor I, metalloproteinases MMP-9, MMP-2, CD44, cytokeratin 19 fragment, tissue polypeptide antigen, CA125, and Cyclin D1 [211-215]. Mass spectrometry-based studies indicated differential expression of several proteins $[209,216]$. The most promising for early identification of oral malignancy could be a panel of five candidate biomarkers (M2BP, MRP14, CD59, profilin, and catalase) or a panel of six proteins (keratin $6 \mathrm{~B}$ (ck6) and 13 (ck13), $\beta$ globin, $\alpha$-2-actin, HSP70, and HSP90) $[209,216]$. Kooren and colleagues showed increased relative abundance of six proteins (hnRNPM, IL1F6, LCN2, S100A8, NQO1, and XRCC5/6) in brush biopsies from the patients with dysplastic oral premalignant lesions compared to saliva collected from the same patients [208].

\section{Conclusions and Future Perspectives}

It is now commonly acknowledged for several cancers that early detection benefits saving lives. Novel, nanotechnologybased, ultrasensitive immune-sensors hold promise to revolutionize cancer detection, monitoring, and therapy in the future with the ability to measure panels of specific, selective cancer biomarker proteins on-the-spot in physicians' surgeries and clinics, together with the development of more accurate proteomic methodologies for clinical laboratory setting [5]. Protein biomarkers, especially when detected in easily accessible clinical samples, such as blood, faces, urine, oral swabs, or saliva, could be of great use in this field. However, the sensitivities and specificities of currently used protein biomarkers are usually too low to be used in clinical setting. It is now well accepted that a single biomarker will not suffice; rather a panel of proteins is necessary to aid in diagnostics. Proteomic studies gave several candidates up to now and with a largescale validation an appropriate combination could be determined.

As can be evident from numerous studies on biomarker discovery for different cancers, several obstacles still hold back translation of research into routine clinical practice. Despite advances in MS-based methods and extensive research, there is still no sensitive and specific serum biomarker panel, which could be used for diagnostic or screening purposes. Discovery and validation of suitable protein biomarkers for noninvasive screening and diagnostics are further impeded by the dynamic complexity of blood, serum, or faeces proteome. Another problem is validation of novel biomarkers and obtaining large cohorts of patients; however, even accumulation of data performed in different research laboratories could eventually contribute to the validation process through meta-analyses. Heterogeneity of sporadic 
cancers implies another obstacle to overcome. The biomarker studies mostly search for novel protein signatures in highly defined patient populations and still different protein changes in individuals across different patient populations are found, which further limit the translation of discovered biomarkers into clinical setting. For general screening purposes, multicentred large studies and meta-analyses should be performed in order to improve the accuracy and sensitivity of the test.

$\begin{array}{ll}\text { Abbreviations } \\ \text { 2DE: } & \text { Two-dimensional gel electrophoresis } \\ \text { 2D-DIGE: } & \text { Difference gel electrophoresis } \\ \text { CBB: } & \text { Coomassie Brilliant Blue } \\ \text { CIMP: } & \text { CpG island methylator phenotype } \\ \text { ESI: } & \text { Electrospray ionisation } \\ \text { FAP: } & \text { Familial adenomatous polyposis } \\ \text { ICAT: } & \text { Isotope-coded affinity tag } \\ \text { IEF: } & \text { Isoelectric focusing } \\ \text { iTRAQ: } & \text { Isobaric tags for relative and absolute } \\ & \text { quantitation } \\ \text { LC: } & \text { Liquid chromatography } \\ \text { MALDI-TOF: } & \text { Matrix-assisted laser } \\ & \text { desorption/ionization time-of-flight } \\ \text { MAP: } & \text { MUTYH-associated polyposis } \\ \text { MMR: } & \text { Mismatch repair } \\ \text { MS: } & \text { Mass spectrometry } \\ \text { MS/MS: } & \text { Tandem mass spectrometry } \\ \text { MSI: } & \text { Microsatellite instability } \\ \text { pI: } & \text { Isoelectric point } \\ \text { PTM: } & \text { Posttranslational modification } \\ \text { SDS-PAGE: } & \text { Polyacrylamide gel electrophoresis } \\ \text { SILAC: } & \text { Stable isotope labelling by amino } \\ & \text { acids in cell culture. }\end{array}$

\section{Conflict of Interests}

The authors declare no conflict of interests.

\section{Acknowledgment}

The authors would like to thank the Operational Programme Italy-Slovenia 2007-2013 (Project GLIOMA) for the financial support.

\section{References}

[1] A. N. Bhatt, R. Mathur, A. Farooque, A. Verma, and B. S. Dwarakanath, "Cancer biomarkers-current perspectives," The Indian Journal of Medical Research, vol. 132, no. 8, pp. 129-149, 2010.

[2] G. L. Hortin, S. A. Carr, and N. L. Anderson, "Introduction: advances in protein analysis for the clinical laboratory," Clinical Chemistry, vol. 56, no. 2, pp. 149-151, 2010.

[3] M. W. Qoronfleh and K. Lindpaintner, "Protein biomarker immunoassays opportunities and challenges," Drug Discovery World, vol. 11, no. 1, pp. 19-28, 2010.

[4] K. Honda, M. Ono, M. Shitashige et al., "Proteomic approaches to the discovery of cancer biomarkers for early detection and personalized medicine," Japanese Journal of Clinical Oncology, vol. 43, no. 2, pp. 103-109, 2013.

[5] J. F. Rusling, C. V. Kumar, J. S. Gutkind, and V. Patel, "Measurement of biomarker proteins for point-of-care early detection and monitoring of cancer," Analyst, vol. 135, no. 10, pp. 24962511, 2010.

[6] S. Kumar, A. Mohan, and R. Guleria, "Biomarkers in cancer screening, research and detection: present and future: a review," Biomarkers, vol. 11, no. 5, pp. 385-405, 2006.

[7] T. H. Ågesen, A. Sveen, M. A. Merok et al., "ColoGuideEx: a robust gene classifier specific for stage II colorectal cancer prognosis," Gut, vol. 61, pp. 1560-1567, 2012.

[8] M. R. Cooperberg, J. P. Simko, J. E. Cowan et al., "Validation of a cell-cycle progression gene panel to improve risk stratification in a contemporary prostatectomy cohort," Journal of Clinical Oncology, vol. 31, pp. 1428-1434, 2013.

[9] J. Cuzick, D. M. Berney, G. Fisher et al., "Prognostic value of a cell cycle progression signature for prostate cancer death in a conservatively managed needle biopsy cohort," British Journal of Cancer, vol. 106, no. 6, pp. 1095-1099, 2012.

[10] J. Cuzick, G. P. Swanson, G. Fisher et al., "Prognostic value of an RNA expression signature derived from cell cycle proliferation genes in patients with prostate cancer: a retrospective study," The Lancet Oncology, vol. 12, no. 3, pp. 245-255, 2011.

[11] R. D. Kennedy, M. Bylesjo, P. Kerr et al., "Development and independent validation of a prognostic assay for stage II colon cancer using formalin-fixed paraffin-embedded tissue," Journal of Clinical Oncology, vol. 29, no. 35, pp. 4620-4626, 2011.

[12] K. M. Clark-Langone, C. Sangli, J. Krishnakumar, and D. Watson, "Translating tumor biology into personalized treatment planning: analytical performance characteristics of the oncotype DX colon cancer assay," BMC Cancer, vol. 10, article 691, 2010.

[13] M. Maak, I. Simon, U. Nitsche et al., "Independent validation of a prognostic genomic signature (ColoPrint) for patients with stage II colon cancer," Annals of Surgery, vol. 257, no. 6, pp. 10531058, 2013.

[14] L. J. van't Veer, H. Dai, M. J. van de Vijver et al., "Gene expression profiling predicts clinical outcome of breast cancer," Nature, vol. 415, no. 6871, pp. 530-536, 2002.

[15] R. Salazar, P. Roepman, G. Capella et al., "Gene expression signature to improve prognosis prediction of stage II and III colorectal cancer," Journal of Clinical Oncology, vol. 29, no. 1, pp. 17-24, 2011.

[16] Y. Y. Park, S. S. Lee, J. Y. Lim et al., “Comparison of prognostic genomic predictors in colorectal cancer," PloS ONE, vol. 8, no. 4, Article ID e60778, 2013.

[17] A. Sveen, T. H. Agesen, A. Nesbakken et al., "ColoGuidePro: a prognostic 7-gene expression signature for stage III colorectal cancer patients," Clinical Cancer Research, vol. 18, pp. 6001-6010, 2012.

[18] C. Chen, H. Huang, and C. H. Wu, "Protein bioinformatics databases and resources," Methods in Molecular Biology, vol. 694, pp. 3-24, 2011.

[19] S. Hanash, M. Schliekelman, Q. Zhang, and A. Taguchi, "Integration of proteomics into systems biology of cancer," Wiley Interdisciplinary Reviews, vol. 4, no. 4, pp. 327-337, 2012.

[20] F. K. Pontén, J. M. Schwenk, A. Asplund, and P.-H. D. Edqvist, "The human protein atlas as a proteomic resource for biomarker discovery," Journal of Internal Medicine, vol. 270, no. 5, pp. 428446, 2011. 
[21] K. X. Zhang and B. F. F. Ouellette, "CAERUS: predicting cancer outcomes using relationship between protein structural information, protein networks, gene expression data, and mutation data," PLoS Computational Biology, vol. 7, no. 3, Article ID e1001114, 2011.

[22] L. Chin and J. W. Gray, "Translating insights from the cancer genome into clinical practice," Nature, vol. 452, no. 7187, pp. 553-563, 2008.

[23] P. Hudler, M. Gorsic, and R. Komel, "Proteomic strategies and challenges in tumor metastasis research," Clinical \& Experimental Metastasis, vol. 27, no. 6, pp. 441-451, 2010.

[24] S. Hanash, "Progress in mining the human proteome for disease applications," OMICS, vol. 15, no. 3, pp. 133-139, 2011.

[25] J. P. Savaryn, A. D. Catherman, P. M. Thomas, M. M. Abecassis, and N. L. Kelleher, "The emergence of top-down proteomics in clinical research," Genome Medicine, vol. 5, article 53, 2013.

[26] K. E. Hung and K. H. Yu, "Proteomic approaches to cancer biomarkers," Gastroenterology, vol. 138, no. 1, pp. 46.el-51.el, 2010.

[27] J. A. Ludwig and J. N. Weinstein, "Biomarkers in cancer staging, prognosis and treatment selection," Nature Reviews, vol. 5, no. 11, pp. 845-856, 2005.

[28] S. Hanash and A. Taguchi, "The grand challenge to decipher the cancer proteome," Nature Reviews, vol. 10, no. 9, pp. 652-660, 2010.

[29] A. Izzotti, "Molecular medicine and the development of cancer chemopreventive agents," Annals of the New York Academy of Sciences, vol. 1259, pp. 26-32, 2012.

[30] S. Bhatia, J. V. Frangioni, R. M. Hoffman, A. J. Iafrate, and K. Polyak, "The challenges posed by cancer heterogeneity," Nature Biotechnology, vol. 30, no. 7, pp. 604-610, 2012.

[31] N. Murugaesu, S. K. Chew, and C. Swanton, "Adapting clinical paradigms to the challenges of cancer clonal evolution," The American Journal of Pathology, vol. 182, pp. 1962-1971, 2013.

[32] E. B. Barbosa, A. Vidotto, G. M. Polachini, T. Henrique, A. B. Marqui, and E. H. Tajara, "Proteomics: methodologies and applications to the study of human diseases," Revista da Associacao Medica Brasileira, vol. 58, no. 3, pp. 366-375, 2012.

[33] A. F. Altelaar, J. Munoz, and A. J. Heck, "Next-generation proteomics: towards an integrative view of proteome dynamics," Nature Reviews, vol. 14, pp. 35-48, 2013.

[34] M. Claassen, "Inference and validation of protein identifications," Molecular \&Cellular Proteomics, vol. 11, pp. 1097-1104, 2012.

[35] H. Zhou, Z. Ning, A. E. Starr, M. Abu-Farha, and D. Figeys, "Advancements in top-down proteomics," Analytical Chemistry, vol. 84, no. 2, pp. 720-734, 2012.

[36] P. H. O'Farrell, "High resolution two dimensional electrophoresis of proteins," The Journal of Biological Chemistry, vol. 250, no. 10, pp. 4007-4021, 1975.

[37] T. Rabilloud, M. Chevallet, S. Luche, and C. Lelong, “Twodimensional gel electrophoresis in proteomics: past, present and future," Journal of Proteomics, vol. 73, no. 11, pp. 2064-2077, 2010.

[38] J. S. Minden, "DIGE: past and future," Methods in Molecular Biology, vol. 854, pp. 3-8, 2012.

[39] P. Roepstorff, "Mass spectrometry based proteomics, background, status and future needs," Protein \& Cell, vol. 3, pp. 641647, 2012.

[40] M. Bantscheff, S. Lemeer, M. M. Savitski, and B. Kuster, "Quantitative mass spectrometry in proteomics: critical review update from 2007 to the present," Analytical and Bioanalytical Chemistry, vol. 404, pp. 939-965, 2012.

[41] S.-E. Ong, B. Blagoev, I. Kratchmarova et al., "Stable isotope labeling by amino acids in cell culture, SILAC, as a simple and accurate approach to expression proteomics," Molecular \& Cellular Proteomics, vol. 1, no. 5, pp. 376-386, 2002.

[42] S. P. Gygi, B. Rist, S. A. Gerber, F. Turecek, M. H. Gelb, and R. Aebersold, "Quantitative analysis of complex protein mixtures using isotope-coded affinity tags," Nature Biotechnology, vol. 17, no. 10, pp. 994-999, 1999.

[43] R. D. Unwin, A. Pierce, R. B. Watson, D. W. Sternberg, and A. D. Whetton, "Quantitative proteomic analysis using isobaric protein tags enables rapid comparison of changes in transcript and protein levels in transformed cells," Molecular \& Cellular Proteomics, vol. 4, no. 7, pp. 924-935, 2005.

[44] P. L. Ross, Y. N. Huang, J. N. Marchese et al., "Multiplexed protein quantitation in Saccharomyces cerevisiae using aminereactive isobaric tagging reagents," Molecular \& Cellular Proteomics, vol. 3, no. 12, pp. 1154-1169, 2004.

[45] A. Thompson, J. Schäfer, K. Kuhn et al., “Tandem mass tags: a novel quantification strategy for comparative analysis of complex protein mixtures by MS/MS," Analytical Chemistry, vol. 75, no. 8, pp. 1895-1904, 2003.

[46] J. M. Asara, H. R. Christofk, L. M. Freimark, and L. C. Cantley, "A label-free quantification method by MS/MS TIC compared to SILAC and spectral counting in a proteomics screen," Proteomics, vol. 8, no. 5, pp. 994-999, 2008.

[47] T. S. Collier, S. M. Randall, P. Sarkar, B. M. Rao, R. A. Dean, and D. C. Muddiman, "Comparison of stable-isotope labeling with amino acids in cell culture and spectral counting for relative quantification of protein expression," Rapid Communications in Mass Spectrometry, vol. 25, no. 17, pp. 2524-2532, 2011.

[48] H. Liu, R. G. Sadygov, and J. R. Yates III, "A model for random sampling and estimation of relative protein abundance in shotgun proteomics," Analytical Chemistry, vol. 76, no. 14, pp. 4193-4201, 2004.

[49] H. Steen, J. A. Jebanathirajah, M. Springer, and M. W. Kirschner, "Stable isotope-free relative and absolute quantitation of protein phosphorylation stoichiometry by MS," Proceedings of the National Academy of Sciences of the United States of America, vol. 102, no. 11, pp. 3948-3953, 2005.

[50] Y.-G. Tsay, Y.-H. Wang, C.-M. Chiu, B.-J. Shen, and S.-C. Lee, “A strategy for identification and quantitation of phosphopeptides by liquid chromatography/tandem mass spectrometry," Analytical Biochemistry, vol. 287, no. 1, pp. 55-64, 2000.

[51] W. Wang, H. Zhou, H. Lin et al., "Quantification of proteins and metabolites by mass spectrometry without isotopic labeling or spiked standards," Analytical Chemistry, vol. 75, no. 18, pp. 48184826, 2003.

[52] B. Zhang, N. C. VerBerkmoes, M. A. Langston, E. Uberbacher, R. L. Hettich, and N. F. Samatova, "Detecting differential and correlated protein expression in label-free shotgun proteomics," Journal of Proteome Research, vol. 5, no. 11, pp. 2909-2918, 2006.

[53] H. Zhu and J. Qian, "Applications of functional protein microarrays in basic and clinical research," Advances in Genetics, vol. 79, pp. 123-155, 2012.

[54] S.-H. Chiou and C.-Y. Wu, "Clinical proteomics: current status, challenges, and future perspectives," Kaohsiung Journal of Medical Sciences, vol. 27, no. 1, pp. 1-14, 2011.

[55] S. Hanash, "A call for a fresh new look at the plasma proteome," Proteomics, vol. 6, no. 9-10, pp. 443-446, 2012. 
[56] E. Pin, C. Fredolini, and E. F. Petricoin 3rd, "The role of proteomics in prostate cancer research: biomarker discoveary and validation," Clinical Biochemistry, vol. 46, pp. 524-538, 2013.

[57] S. Pitteri and S. Hanash, "A systems approach to the proteomic identification of novel cancer biomarkers," Disease Markers, vol. 28, no. 4, pp. 233-239, 2010.

[58] J. Ferlay, H.-R. Shin, F. Bray, D. Forman, C. Mathers, and D. M. Parkin, "Estimates of worldwide burden of cancer in 2008: GLOBOCAN 2008," International Journal of Cancer, vol. 127, no. 12, pp. 2893-2917, 2010.

[59] A. J. Alberg, M. V. Brock, J. G. Ford, J. M. Samet, and S. D. Spivack, "Epidemiology of lung cancer: diagnosis and management of lung cancer, 3rd ed: American College of Chest Physicians evidence-based clinical practice guidelines," Chest, vol. 143, pp. e1S-e29S, 2013.

[60] W. D. Foulkes, "Inherited susceptibility to common cancers," The New England Journal of Medicine, vol. 359, no. 20, pp. 21432153, 2008.

[61] D. W. Bell, I. Gore, R. A. Okimoto et al., "Inherited susceptibility to lung cancer may be associated with the T790M drug resistance mutation in EGFR," Nature Genetics, vol. 37, no. 12, pp. 1315-1316, 2005.

[62] K. Ohtsuka, H. Ohnishi, D. Kurai et al., "Familial lung adenocarcinoma caused by the EGFR V843I germ-line mutation," Journal of Clinical Oncology, vol. 29, no. 8, pp. e191-e192, 2011.

[63] P. A. Bunn Jr, "Worldwide overview of the current status of lung cancer diagnosis and treatment," Archives of Pathology \& Laboratory Medicine, vol. 136, pp. 1478-1481, 2012.

[64] S. P. Nana-Sinkam and C. A. Powell, "Molecular biology of lung cancer: diagnosis and management of lung cancer, 3rd ed: American College of Chest Physicians evidence-based clinical practice guidelines," Chest, vol. 143, no. 5, pp. e30S-e39S, 2013.

[65] F. C. Detterbeck, P. J. Mazzone, D. P. Naidich, and P. B. Bach, "Screening for lung cancer: diagnosis and management of lung cancer, 3rd ed: American College of Chest Physicians evidencebased clinical practice guidelines," Chest, vol. 143, no. 5, pp. e78S-e92S, 2013.

[66] P. Boyle, C. J. Chapman, S. Holdenrieder et al., "Clinical validation of an autoantibody test for lung cancer," Annals of Oncology, vol. 22, no. 2, pp. 383-389, 2011.

[67] A. Murray, C. J. Chapman, G. Healey et al., "Technical validation of an autoantibody test for lung cancer," Annals of Oncology, vol. 21, no. 8, pp. 1687-1693, 2010.

[68] P. Indovina, E. Marcelli, F. Pentimalli, P. Tanganelli, G. Tarro, and A. Giordano, "Mass spectrometry-based proteomics: the road to lung cancer biomarker discovery," Mass Spectrometry Reviews, vol. 32, pp. 129-142, 2013.

[69] A. T. Y. Lau and J.-F. Chiu, "Biomarkers of lung-related diseases: current knowledge by proteomic approaches," Journal of Cellular Physiology, vol. 221, no. 3, pp. 535-543, 2009.

[70] S. Ocak, P. Chaurand, and P. P. Massion, "Mass spectrometrybased proteomic profiling of lung cancer," Proceedings of the American Thoracic Society, vol. 6, no. 2, pp. 159-170, 2009.

[71] M. Hassanein, J. C. Callison, C. Callaway-Lane, M. C. Aldrich, E. L. Grogan, and P. P. Massion, "The state of molecular biomarkers for the early detection of lung cancer," Cancer Prevention Research, vol. 5, pp. 992-1006, 2012.

[72] S. Ocak, M. L. Sos, R. K. Thomas, and P. P. Massion, "Highthroughput molecular analysis in lung cancer: insights into biology and potential clinical applications," The European Respiratory Journal, vol. 34, no. 2, pp. 489-506, 2009.
[73] J. Lehtiö and L. de Petris, "Lung cancer proteomics, clinical and technological considerations," Journal of Proteomics, vol. 73, no. 10, pp. 1851-1863, 2010.

[74] X. Zhou, L. Xue, L. Hao et al., "Proteomics-based identification of tumor relevant proteins in lung adenocarcinoma," Biomedicine \& Pharmacotherapy, vol. 67, no. 7, pp. 621-627, 2013.

[75] F. Tan, Y. Jiang, N. Sun et al., "Identification of isocitrate dehydrogenase 1 as a potential diagnostic and prognostic biomarker for non-small cell lung cancer by proteomic analysis," Molecular \& Cellular Proteomics, vol. 11, no. 2, Article ID M111.008821, 2012.

[76] K. Chung, N. Nishiyama, S. Yamano et al., "Serum AGR2 as an early diagnostic and postoperative prognostic biomarker of human lung adenocarcinoma," Cancer Biomarkers, vol. 10, no. 2, pp. 101-107, 2011.

[77] A. Gámez-Pozo, I. Sánchez-Navarro, E. Calvo et al., "PTRF/ Cavin-1 and MIF proteins are identified as non-small cell lung cancer biomarkers by label-free proteomics," PLOS ONE, vol. 7, no. 3, Article ID e33752, 2012.

[78] Y. He, Z. Zhou, W. L. Hofstetter et al., "Aberrant expression of proteins involved in signal transduction and DNA repair pathways in lung cancer and their association with clinical parameters," PLoS ONE, vol. 7, no. 2, Article ID e31087, 2012.

[79] G. Q. Zeng, P. F. Zhang, X. Deng et al., "Identification of candidate biomarkers for early detection of human lung squamous cell cancer by quantitative proteomics," Molecular \& Cellular Proteomics, vol. 11, no. 6, Article ID M111.013946, 2012.

[80] H. S. Lee, J. W. Park, O. Chertov et al., "Matrix-assisted laser desorption/ionization mass spectrometry reveals decreased calcylcin expression in small cell lung cancer," Pathology International, vol. 62, no. 1, pp. 28-35, 2012.

[81] G. H. Li, Y. S. Cui, Q. Y. Wu, X. J. Zhang, and Y. F. Gao, "Clinicopathologic significance of beta-catenin and matrix metalloproteinase-2 expression in non-small cell lung cancer," Medical Oncology, vol. 30, article 437, 2013.

[82] W. Heng, C. Y. Mu, C. Chen, J. A. Huang, and Z. Y. Wang, "Endothelial cell protein C receptor (EPCR) is expressed by lung carcinoma and correlated with clinical parameters," Clinical Laboratory, vol. 59, pp. 375-380, 2013.

[83] Z. K. Liang, Y. J. Yin, E. D. Wu, and G. L. Shi, "The clinical value of new tumor biomarker cytokeratin 2G2 detection in non-small cell lung cancer patients," Clinical Laboratory, vol. 59, pp. 551-556, 2013.

[84] X. J. Li, Q. F. Wu, D. L. He, J. K. Fu, and X. Jin, "Proteomic profiling of serum from stage I lung squamous cell carcinoma patients," Asian Pacific Journal of Cancer Prevention, vol. 14, no. 4, pp. 2273-2276, 2013.

[85] J. H. Kang, T. Mori, H. Kitazaki et al., "Kinase activity of protein kinase calpha in serum as a diagnostic biomarker of human lung cancer," Anticancer Research, vol. 33, pp. 485-488, 2013.

[86] Y. Liu, X. Luo, H. Hu et al., "Integrative proteomics and tissue microarray profiling indicate the association between overexpressed serum proteins and non-small cell lung cancer," PloS ONE, vol. 7, no. 12, Article ID e51748, 2012.

[87] G. Higgins, K. M. Roper, I. J. Watson et al., "Variant Ciz1 is a circulating biomarker for early-stage lung cancer," Proceedings of the National Academy of Sciences of the United States of America, vol. 109, pp. E3128-E3135, 2012.

[88] M. D. Pastor, A. Nogal, S. Molina-Pinelo et al., "Identification of proteomic signatures associated with lung cancer and COPD," Journal of Proteomics, vol. 89, p. 227, 2013. 
[89] J. Ligibel, "Lifestyle factors in cancer survivorship," Journal of Clinical Oncology, vol. 30, pp. 3697-3704, 2012.

[90] A. D. Corben, "Pathology of invasive breast disease," The Surgical Clinics of North America, vol. 93, pp. 363-392, 2013.

[91] U. O. Njiaju and O. I. Olopade, "Genetic determinants of breast cancer risk: a review of current literature and issues pertaining to clinical application," The Breast Journal, vol. 18, pp. 436-442, 2012.

[92] C. S. Giess, E. P. Frost, and R. L. Birdwell, "Difficulties and errors in diagnosis of breast neoplasms," Seminars in Ultrasound, CT, and $M R$, vol. 33, no. 4, pp. 288-299, 2012.

[93] S. S. Tang and G. P. Gui, "Biomarkers in the diagnosis of primary and recurrent breast cancer," Biomarkers in Medicine, vol. 6, no. 5, pp. 567-585, 2012.

[94] R. R. Drake, L. H. Cazares, E. E. Jones, T. W. Fuller, O. J. Semmes, and C. Laronga, "Challenges to developing proteomic-based breast cancer diagnostics," OMICS, vol. 15, no. 5, pp. 251-259, 2011.

[95] E. R. C. G. N. Galvão, L. M. S. Martins, J. O. Ibiapina, H. M. Andrade, and S. J. H. Monte, "Breast cancer proteomics: a review for clinicians," Journal of Cancer Research and Clinical Oncology, vol. 137, no. 6, pp. 915-925, 2011.

[96] A. W. J. Opstal-van Winden, R. C. H. Vermeulen, P. H. M. Peeters, J. H. Beijnen, and C. H. van Gils, "Early diagnostic protein biomarkers for breast cancer: how far have we come?" Breast Cancer Research and Treatment, vol. 134, pp. 1-12, 2011.

[97] P. Cancemi, G. Di Cara, N. N. Albanese et al., "Large-scale proteomic identification of S100 proteins in breast cancer tissues," BMC Cancer, vol. 10, article no. 476, 2010.

[98] M. Kabbage, M. Trimeche, S. Bergaoui et al., "Calreticulin expression in infiltrating ductal breast carcinomas: relationships with disease progression and humoral immune responses," Tumour Biology, vol. 34, no. 2, pp. 1177-1188, 2013.

[99] M. N. Song, P. G. Moon, J. E. Lee et al., "Proteomic analysis of breast cancer tissues to identify biomarker candidates by gelassisted digestion and label-free quantification methods using LC-MS/MS", Archives of Pharmacal Research, vol. 35, no. 10, pp. 1839-1847, 2012.

[100] S. Saini, N. Jagadish, A. Gupta, A. Bhatnagar, and A. Suri, "A novel cancer testis antigen, A-kinase anchor protein 4 (AKAP4) is a potential biomarker for breast cancer," PloS ONE, vol. 8, Article ID e57095, 2013.

[101] Y. Huang, H. Zhang, J. Cai et al., "Overexpression of MACC1 and Its significance in human breast cancer progression," Cell \& Bioscience, vol. 3, article 16, 2013.

[102] M. Xiao, S. Jia, H. Wang, J. Wang, Y. Huang, and Z. Li, "Overexpression of LAPTM4B: an independent prognostic marker in breast cancer," Journal of Cancer Research and Clinical Oncology, vol. 139, no. 4, pp. 661-667, 2013.

[103] E. Shubbar, K. Helou, A. Kovacs et al., "High levels of gammaglutamyl hydrolase (GGH) are associated with poor prognosis and unfavorable clinical outcomes in invasive breast cancer," BMC Cancer, vol. 13, article 47, 2013.

[104] W. J. Lian, G. Liu, Y. J. Liu, Z. W. Zhao, T. Yi, and H. Y. Zhou, "Downregulation of BMP6 enhances cell proliferation and chemoresistance via activation of the ERK signaling pathway in breast cancer," Oncology Reports, vol. 30, pp. 193-200, 2013.

[105] L. Zhu, X. Song, J. Tang et al., "Huntingtin-associated protein 1: a potential biomarker of breast cancer," Oncology Reports, vol. 29, pp. 1881-1887, 2013.
[106] Z. Zeng, M. Hincapie, S. J. Pitteri et al., "A proteomics platform combining depletion, multi-lectin affinity chromatography (MLAC), and isoelectric focusing to study the breast cancer proteome," Analytical Chemistry, vol. 83, no. 12, pp. 4845-4854, 2011.

[107] M. Xiang, W. Zhou, D. Gao, X. Fang, and Q. Liu, "Inhibitor of apoptosis protein-like protein-2 as a novel serological biomarker for breast cancer," International Journal of Molecular Sciences, vol. 13, no. 12, pp. 16737-16750, 2012.

[108] U.-B. Kang, Y. Ahn, J. W. Lee et al., "Differential profiling of breast cancer plasma proteome by isotope-coded affinity tagging method reveals biotinidase as a breast cancer biomarker," BMC Cancer, vol. 10, article 114, 2010.

[109] E. J. Suh, M. H. Kabir, U.-B. Kang et al., "Comparative profiling of plasma proteome from breast cancer patients reveals thrombospondin-1 and BRWD3 as serological biomarkers," Experimental \& Molecular Medicine, vol. 44, no. 1, pp. 36-44, 2012.

[110] L. Zhang, H. Xiao, S. Karlan et al., "Discovery and preclinical validation of salivary transcriptomic and proteomic biomarkers for the non- invasive detection of breast cancer," PLoS ONE, vol. 5, no. 12, Article ID e15573, 2010.

[111] D. Bohm, K. Keller, J. Pieter et al., "Comparison of tear protein levels in breast cancer patients and healthy controls using a de novo proteomic approach," Oncology Reports, vol. 28, pp. 429438, 2012.

[112] A. Jemal, M. M. Center, C. DeSantis, and E. M. Ward, "Global patterns of cancer incidence and mortality rates and trends," Cancer Epidemiology Biomarkers and Prevention, vol. 19, no. 8, pp. 1893-1907, 2010.

[113] R. M. Bambury and D. J. Gallagher, "Prostate cancer: germline prediction for a commonly variable malignancy," BJU International, vol. 110, no. 11, pp. E809-E818, 2012.

[114] E. Castro, C. Goh, D. Olmos et al., "Germline BRCA mutations are associated with higher risk of nodal involvement, distant metastasis, and poor survival outcomes in prostate cancer," Journal of Clinical Oncology, vol. 31, pp. 1748-1757, 2013.

[115] M. K. Sorongon-Legaspi, M. Chua, M. C. Sio, M. Morales Jr. "Blood level omega-3 fatty acids as risk determinant molecular biomarker for prostate cancer," Prostate Cancer, vol. 2013, Article ID 875615, 15 pages, 2013.

[116] R. A. Eeles, Z. Kote-Jarai, A. A. Al Olama et al., "Identification of seven new prostate cancer susceptibility loci through a genomewide association study," Nature Genetics, vol. 41, no. 10, pp. 11161121, 2009.

[117] J. Gudmundsson, P. Sulem, D. F. Gudbjartsson et al., "Genomewide association and replication studies identify four variants associated with prostate cancer susceptibility," Nature Genetics, vol. 41, no. 10, pp. 1122-1126, 2009.

[118] M. Guy, Z. Kote-Jarai, G. G. Giles et al., "Identification of new genetic risk factors for prostate cancer," Asian Journal of Andrology, vol. 11, no. 1, pp. 49-55, 2009.

[119] Z. Kote-Jarai, A. A. A. Olama, G. G. Giles et al., "Seven prostate cancer susceptibility loci identified by a multi-stage genomewide association study," Nature Genetics, vol. 43, no. 8, pp. 785791, 2011.

[120] J. Chen, D. Zhang, W. Yan, D. Yang, and B. Shen, “Translational bioinformatics for diagnostic and prognostic prediction of prostate cancer in the next-generation sequencing era," BioMed Research International, vol. 2013, Article ID 901578, 13 pages, 2013. 
[121] V. Zieglschmid, C. Hollmann, and O. Böcher, "Detection of disseminated tumor cells in peripheral blood," Critical Reviews in Clinical Laboratory Sciences, vol. 42, no. 2, pp. 155-196, 2005.

[122] O. Sartor, "Randomized studies of PSA screening: an opinion," Asian Journal of Andrology, vol. 13, no. 3, pp. 364-365, 2011.

[123] G. P. Haas, "New developments in prostate cancer screening and prevention," The Canadian Journal of Urology, vol. 16, no. 3, article 4624, 2009.

[124] L. D. F. Venderbos and M. J. Roobol, “PSA-based prostate cancer screening: the role of active surveillance and informed and shared decision making," Asian Journal of Andrology, vol. 13, no. 2, pp. 219-224, 2011.

[125] N. Kachroo and V. J. Gnanapragasam, “The role of treatment modality on the utility of predictive tissue biomarkers in clinical prostate cancer: a systematic review," Journal of Cancer Research and Clinical Oncology, vol. 139, pp. 1-24, 2013.

[126] I. Rehman, C. A. Evans, A. Glen et al., "iTRAQ identification of candidate serum biomarkers associated with metastatic progression of human prostate cancer," PLoS ONE, vol. 7, no. 2, Article ID e30885, 2012.

[127] I. Katafigiotis, S. I. Tyritzis, K. G. Stravodimos et al., "Zinc alpha2-glycoprotein as a potential novel urine biomarker for the early diagnosis of prostate cancer," BJU International, vol. 110, pp. E688-E693, 2012.

[128] M. I. Hassan, V. Kumar, T. Kashav, N. Alam, T. P. Singh, and S. Yadav, "Proteomic approach for purification of seminal plasma proteins involved in tumor proliferation," Journal of Separation Science, vol. 30, no. 12, pp. 1979-1988, 2007.

[129] S. M. Henshall, L. G. Horvath, D. I. Quinn et al., "Zinc-alpha2glycoprotein expression as a predictor of metastatic prostate cancer following radical prostatectomy," Journal of the National Cancer Institute, vol. 98, no. 19, pp. 1420-1424, 2006.

[130] I. Cima, R. Schiess, P. Wild et al., "Cancer genetics-guided discovery of serum biomarker signatures for diagnosis and prognosis of prostate cancer," Proceedings of the National Academy of Sciences of the United States of America, vol. 108, no. 8, pp. 3342-3347, 2011.

[131] M. Gross, I. Top, I. Laux et al., " $\beta$-2-microglobulin is an androgen-regulated secreted protein elevated in serum of patients with advanced prostate cancer," Clinical Cancer Research, vol.13, no. 7, pp. 1979-1986, 2007.

[132] D. Theodorescu, E. Schiffer, H. W. Bauer et al., "Discovery and validation of urinary biomarkers for prostate cancer," Proteomics, vol. 2, no. 4, pp. 556-570, 2008.

[133] E. Schiffer, C. Bick, B. Grizelj, S. Pietzker, and W. Schöfer, "Urinary proteome analysis for prostate cancer diagnosis: Costeffective application in routine clinical practice in Germany," International Journal of Urology, vol. 19, no. 2, pp. 118-125, 2012.

[134] J. C. Byrne, M. R. Downes, N. O’Donoghue et al., “2D-DIGE as a strategy to identify serum markers for the progression of prostate cancer," Journal of Proteome Research, vol. 8, no. 2, pp. 942-957, 2009.

[135] V. Michalaki, K. Syrigos, P. Charles, and J. Waxman, "Serum levels of IL- 6 and TNF- $\alpha$ correlate with clinicopathological features and patient survival in patients with prostate cancer," British Journal of Cancer, vol. 90, no. 12, pp. 2312-2316, 2004.

[136] R. Morgan, A. Boxall, A. Bhatt et al., "Engrailed-2 (EN2): a tumor specific urinary biomarker for the early diagnosis of prostate cancer," Clinical Cancer Research, vol. 17, no. 5, pp. 1090-1098, 2011.
[137] G. Sardana, K. Jung, C. Stephan, and E. P. Diamandis, "Proteomic analysis of conditioned media from the PC3, LNCaP, and 22Rvl prostate cancer cell lines: discovery and validation of candidate prostate cancer biomarkers," Journal of Proteome Research, vol. 7, no. 8, pp. 3329-3338, 2008.

[138] H. J. Wanebo, M. LeGolvan, P. B. Paty et al., "Meeting the biologic challenge of colorectal metastases," Clinical \& Experimental Metastasis, vol. 29, pp. 821-839, 2012.

[139] D. L. Worthley and B. A. Leggett, "Colorectal cancer: molecular features and clinical opportunities," The Clinical Biochemist Reviews, vol. 31, no. 2, pp. 31-38, 2010.

[140] L. Moreira, F. Balaguer, N. Lindor et al., "Identification of Lynch syndrome among patients with colorectal cancer," The Journal of the American Medical Association, vol. 308, pp. 1555-1565, 2012.

[141] N. Al-Tassan, N. H. Chmiel, J. Maynard et al., "Inherited variants of MYH associated with somatic $\mathrm{G}: \mathrm{C} \rightarrow \mathrm{T}: \mathrm{A}$ mutations in colorectal tumors," Nature Genetics, vol. 30, no. 2, pp. 227$232,2002$.

[142] K. Oishi, S. Hofmann, G. A. Diaz et al., "Biallelic germline mutations in $\mathrm{MYH}$ predispose to multiple colorectal adenoma and somatic G:C $\rightarrow$ T:A mutations," Human Molecular Genetics, vol. 11, no. 23, pp. 2961-2967, 2002.

[143] E. Theodoratou, H. Campbell, A. Tenesa et al., "A largescale meta-analysis to refine colorectal cancer risk estimates associated with MUTYH variants," British Journal of Cancer, vol. 103, no. 12, pp. 1875-1884, 2010.

[144] P. Galiatsatos and W. D. Foulkes, "Familial adenomatous polyposis," The American Journal of Gastroenterology, vol. 101, no. 2, pp. 385-398, 2006.

[145] E. Half, D. Bercovich, and P. Rozen, "Familial adenomatous polyposis," Orphanet Journal of Rare Diseases, vol. 4, no. 1, article 22, 2009.

[146] C. C. Pritchard and W. M. Grady, "Colorectal cancer molecular biology moves into clinical practice," Gut, vol. 60, no. 1, pp. 116129, 2011.

[147] K. W. Jasperson, T. M. Tuohy, D. W. Neklason, and R. W. Burt, "Hereditary and familial colon cancer," Gastroenterology, vol. 138, no. 6, pp. 2044-2058, 2010.

[148] L. Camilloni, E. Ferroni, B. J. Cendales et al., "Methods to increase participation in organised screening programs: a systematic review," BMC Public Health, vol. 13, article 464, 2013.

[149] N. Segnan, J. Patnick, L. Karsa v, European Commission, Directorate General for Health, and Consumers, European Guidelines for Quality Assurance in Colorectal Cancer Screening and Diagnosis, Publications Office of the European Union, Luxembourg, 2010.

[150] B. Tepeš, M. Stefanović, M. Bračko et al., "Slovenian colorectal cancer screenig programme SVIT-results of pilot phase," Slovenian Medical Journal, vol. 79, no. 5, pp. 403-411, 2010.

[151] N. Segnan, C. Senore, B. Andreoni et al., "Randomized trial of different screening strategies for colorectal cancer: patient response and detection rates," Journal of the National Cancer Institute, vol. 97, no. 5, pp. 347-357, 2005.

[152] C. Liu, C. Pan, J. Shen, H. Wang, and L. Yong, "MALDITOF MS combined with magnetic beads for detecting serum protein biomarkers and establishment of boosting decision tree model for diagnosis of colorectal cancer," International Journal of Medical Sciences, vol. 8, no. 1, pp. 39-47, 2011.

[153] T. Tanaka, M. Tanaka, T. Tanaka, and R. Ishigamori, "Biomarkers for colorectal cancer," International Journal of Molecular Sciences, vol. 11, no. 9, pp. 3209-3225, 2010. 
[154] K. F. Newton, W. Newman, and J. Hill, "Review of biomarkers in colorectal cancer," Colorectal Disease, vol. 14, no. 1, pp. 3-17, 2012.

[155] H. Tjalsma, "Identification of biomarkers for colorectal cancer through proteomics-based approaches," Expert Review of Proteomics, vol. 7, no. 6, pp. 879-895, 2010.

[156] Merck KGaA, "Cetuximab combined with Irinotecan in Firstline Therapy for Metastatic Colorectal Cancer (CRYSTAL)," ClinicalTrials.Gov NCT00154102, Bethesda, National Library of Medicine U. S., 2005, http://clinicaltrials.gov/ct2/show/results/ NCT00154102.

[157] M. J. Duffy, "Carcinoembryonic antigen as a marker for colorectal cancer: Is it clinically useful?" Clinical Chemistry, vol. 47, no. 4, pp. 624-630, 2001.

[158] S. Novakovic, “Tumor markers in clinical oncology," Radiology and Oncology, vol. 38, pp. 73-83, 2004.

[159] N. M. Sørensen, A. S. Schrohl, V. Jensen, I. J. Christensen, H. J. Nielsen, and N. Brünner, "Comparative studies of tissue inhibitor of metalloproteinases-1 in plasma, serum and tumour tissue extracts from patients with primary colorectal cancer," Scandinavian Journal of Gastroenterology, vol. 43, no. 2, pp. 186191, 2008.

[160] H.-J. Kim, M.-H. Yu, H. Kim, J. Byun, and C. Lee, "Noninvasive molecular biomarkers for the detection of colorectal cancer," BMB Reports, vol. 41, no. 10, pp. 685-692, 2008.

[161] G. Walgenbach-Brunagel, B. Burger, E. S. Leman et al., "The use of a colon cancer associated nuclear antigen CCSA-2 for the blood based detection of colon cancer," Journal of Cellular Biochemistry, vol. 104, no. 1, pp. 286-294, 2008.

[162] D. G. Ward, N. Suggett, Y. Cheng et al., "Identification of serum biomarkers for colon cancer by proteomic analysis," British Journal of Cancer, vol. 94, no. 12, pp. 1898-1905, 2006.

[163] B. Mroczko, M. Groblewska, U. Wereszczyńska-Siemiatkowska et al., "Serum macrophage-colony stimulating factor levels in colorectal cancer patients correlate with lymph node metastasis and poor prognosis," Clinica Chimica Acta, vol. 380, no. 1-2, pp. 208-212, 2007.

[164] J. Y. M. N. Engwegen, H. H. Helgason, A. Cats et al., "Identification of serum proteins discriminating colorectal cancer patients and healthy controls using surface-enhanced laser desorption ionisation-time of flight mass spectrometry," World Journal of Gastroenterology, vol. 12, no. 10, pp. 1536-1544, 2006.

[165] Q. Wang, J. Shen, Z.-F. Li et al., "Limitations in SELDI-TOF MS whole serum proteomic profiling with IMAC surface to specifically detect colorectal cancer," BMC Cancer, vol. 9, article 287, 2009.

[166] N. J. Fan, C. F. Gao, G. Zhao, X. L. Wang, and Q. Y. Liu, "Serum peptidome patterns of breast cancer based on magnetic bead separation and mass spectrometry analysis," Diagnostic Pathology, vol. 7, article 45, 2012.

[167] U.-B. Kang, J. Yeom, H.-J. Kim, H. Kim, and C. Lee, "Expression profiling of more than 3500 proteins of MSS-type colorectal cancer by stable isotope labeling and mass spectrometry," Journal of Proteomics, vol. 75, no. 10, pp. 3050-3062, 2012.

[168] D. Zhao, C. Gao, X. Feng, G. Song, D. Li, and X. Wang, "Identification of colorectal cancer using proteomic patterns in serum," Chinese Journal of Clinical Oncology, vol. 2, no. 2, pp. 583-589, 2005.

[169] H. H. Helgason, J. Y. M. N. Engwegen, M. Zapatka et al., "Identification of serum proteins as prognostic and predictive markers of colorectal cancer using surface enhanced laser desorption ionization-time of flight mass spectrometry," Oncology Reports, vol. 24, no. 1, pp. 57-64, 2010.

[170] S. Klein-Scory, S. Kübler, H. Diehl et al., "Immunoscreening of the extracellular proteome of colorectal cancer cells," BMC Cancer, vol. 10, article 70, 2010.

[171] B. L. Ackermann, "Understanding the role of immunoaffinitybased mass spectrometry methods for clinical applications," Clinical Chemistry, vol. 58, pp. 1620-1622, 2012.

[172] P. J. Halvey, C. R. Ferrone, and D. C. Liebler, "GeLC-MRM quantitation of mutant KRAS oncoprotein in complex biological samples," Journal of Proteome Research, vol. 11, no. 7, pp. 3908-3913, 2012.

[173] I. Ruppen-Canas, P. P. Lopez-Casas, F. Garcia et al., "An improved quantitative mass spectrometry analysis of tumor specific mutant proteins at high sensitivity," Proteomics, vol. 12, no. 9, pp. 1319-1327, 2012.

[174] Q. Wang, R. Chaerkady, J. Wu et al., "Mutant proteins as cancerspecific biomarkers," Proceedings of the National Academy of Sciences of the United States of America, vol. 108, no. 6, pp. 24442449, 2011.

[175] F. Lumachi, F. Marino, R. Orlando, G. B. Chiara, and S. M. M. Basso, "Simultaneous multianalyte immunoassay measurement of five serum tumor markers in the detection of colorectal cancer," Anticancer Research, vol. 32, no. 3, pp. 985-988, 2012.

[176] J. Karl, N. Wild, M. Tacke et al., "Improved diagnosis of colorectal cancer using a combination of fecal occult blood and novel fecal protein markers," Clinical Gastroenterology and Hepatology, vol. 6, no. 10, pp. 1122-1128, 2008.

[177] P. D. Hardt, M. Toepler, B. Ngoumou, J. Rupp, and H. U. Kloer, "Measurement of fecal pyruvate kinase type M2 (tumor M2-PK) concentrations in patients with gastric cancer, colorectal cancer, colorectal adenomas and controls," Anticancer Research, vol. 23, no. 2 A, pp. 851-853, 2003.

[178] U. Haug, S. Hundt, and H. Brenner, "Sensitivity and specificity of faecal tumour M2 pyruvate kinase for detection of colorectal adenomas in a large screening study," British Journal of Cancer, vol. 99, no. 1, pp. 133-135, 2008.

[179] S. A. Mulder, M. E. Van Leerdam, A. J. Van Vuuren et al., "Tumor pyruvate kinase isoenzyme type M2 and immunochemical fecal occult blood test: performance in screening for colorectal cancer," European Journal of Gastroenterology \& Hepatology, vol. 19, no. 10, pp. 878-882, 2007.

[180] Y. M. Shastri, S. Loitsch, N. Hoepffner et al., "Comparison of an established simple office-based immunological FOBT with fecal tumor pyruvate kinase type M2 (M2-PK) for colorectal cancer screening: prospective multicenter study," The American Journal of Gastroenterology, vol. 103, no. 6, pp. 1496-1504, 2008.

[181] Y. M. Shastri, M. Naumann, G. M. Oremek et al., "Prospective multicenter evaluation of fecal tumor pyruvate kinase type M2 (M2-PK) as a screening biomarker for colorectal ecoplasia," International Journal of Cancer, vol. 119, no. 11, pp. 2651-2656, 2006.

[182] C. Tonus, M. Sellinger, K. Koss, and G. Neupert, "Faecal pyruvate kinase isoenzyme type M2 for colorectal cancer screening: a meta-analysis," World Journal of Gastroenterology, vol. 18, pp. 4004-4011, 2012.

[183] C.-S. Ang and E. C. Nice, "Targeted in-gel MRM: a hypothesis driven approach for colorectal cancer biomarker discovery in human feces," Journal of Proteome Research, vol. 9, no. 9, pp. 4346-4355, 2010.

[184] C.-S. Ang, J. Rothacker, H. Patsiouras, P. Gibbs, A. W. Burgess, and E. C. Nice, "Use of multiple reaction monitoring for 
multiplex analysis of colorectal cancer-associated proteins in human feces," Electrophoresis, vol. 32, no. 15, pp. 1926-1938, 2011.

[185] L. J. W. Bosch, M. de Wit, G. Oudgenoeg et al., "Stool proteomics reveals new canadidate biomarkers for colorectal cancer screening," Cancer Research, vol. 72, no. 8, supplement 1, 2012, Abstract no. 4523 in "Proceedings of the AACR 103rd Annual Meeting of the American Association for Cancer Research" Chicago, Ill, March 2012.

[186] D. E. Guggenheim and M. A. Shah, "Gastric cancer epidemiology and risk factors," Journal of Surgical Oncology, vol. 107, no. 3, pp. 230-236, 2013.

[187] M. E. Barber, V. Save, F. Carneiro et al., "Histopathological and molecular analysis of gastrectomy specimens from hereditary diffuse gastric cancer patients has implications for endoscopic surveillance of individuals at risk," The Journal of Pathology, vol. 216, no. 3, pp. 286-294, 2008.

[188] P. Lauren, “The two histological main types of gastric carcinoma: diffuse and so-called intestinal-type carcinoma. An attempt at a histo-clinical classification," Acta pathologica et microbiologica Scandinavica, vol. 64, pp. 31-49, 1965.

[189] M. Menges, "Gastric cancer: where is the place for the surgeon, the oncologist and the endoscopist today?" World Journal of Gastrointestinal Oncology, vol. 3, pp. 10-13, 2011.

[190] L.-L. Lin, H.-C. Huang, and H.-F. Juan, "Discovery of biomarkers for gastric cancer: a proteomics approach," Journal of Proteomics, vol. 75, no. 11, pp. 3081-3097, 2012.

[191] N. Kočevar, F. Odreman, A. Vindigni, S. F. Grazio, and R. Komel, "Proteomic analysis of gastric cancer and immunoblot validation of potential biomarkers," World Journal of Gastroenterology, vol. 18, no. 11, pp. 1216-1228, 2012.

[192] J. F. Sousa, A. J. Ham, C. Whitwell et al., "Proteomic profiling of paraffin-embedded samples identifies metaplasia-specific and early-stage gastric cancer biomarkers," The American Journal of Pathology, vol. 181, no. 5, pp. 1560-1572, 2012.

[193] Z. Bu, Z. Zheng, L. Zhang et al., "LGR5 is a promising biomarker for patients with stage I and II gastric cancer," Chinese Journal of Cancer Research, vol. 25, pp. 79-89, 2013.

[194] E. H. Zhao, Z. Y. Shen, H. Liu, X. Jin, and H. Cao, "Clinical significance of human kallikrein 12 gene expression in gastric cancer," World Journal of Gastroenterology, vol. 18, pp. 65976604, 2012.

[195] Y. Yang, W. Toy, L. Y. Choong et al., "Discovery of SLC3A2 cell membrane protein as a potential gastric cancer biomarker: implications in molecular imaging," Journal of Proteome Research, vol. 11, pp. 5736-5747, 2012.

[196] A. Mentese, E. Fidan, A. U. Sumer et al., "Is SCUBE 1 a new biomarker for gastric cancer?" Cancer Biomarkers A, vol. 11, no. 5, pp. 191-195, 2012.

[197] H. S. Ahn, Y. S. Shin, P. J. Park et al., "Serum biomarker panels for the diagnosis of gastric adenocarcinoma," British Journal of Cancer, vol. 106, no. 4, pp. 733-739, 2012.

[198] Y. H. Uen, K. Y. Lin, D. P. Sun et al., "Comparative proteomics, network analysis and post-translational modification identification reveal differential profiles of plasma Con A-bound glycoprotein biomarkers in gastric cancer," Journal of Proteomics, vol. 83, pp. 197-213, 2013.

[199] X. Dong, G. Wang, G. Zhang et al., "The endothelial lipase protein is promising urinary biomarker for diagnosis of gastric cancer," Diagnostic Pathology, vol. 8, article 45, 2013.

[200] A. Huttner, "Overview of primary brain tumors: pathologic classification, epidemiology, molecular biology, and prognostic markers," Hematology/Oncology Clinics of North America, vol. 26, no. 4, pp. 715-732, 2012.

[201] M. L. Goodenberger and R. B. Jenkins, "Genetics of adult glioma," Cancer Genetics, vol. 205, no. 12, pp. 613-621, 2012.

[202] C. S. Jung, A. W. Unterberg, and C. Hartmann, "Diagnostic markers for glioblastoma," Histology and Histopathology, vol. 26, no. 10, pp. 1327-1341, 2011.

[203] K. Somasundaram, M. B. Nijaguna, and D. M. Kumar, "Serum proteomics of glioma: methods and applications," Expert Review of Molecular Diagnostics, vol. 9, no. 7, pp. 695-707, 2009.

[204] J. Kalinina, J. Peng, J. C. Ritchie, and E. G. Van Meir, "Proteomics of gliomas: initial biomarker discovery and evolution of technology," Neuro-Oncology, vol. 13, no. 9, pp. 926-942, 2011.

[205] S. P. Niclou, F. Fack, and U. Rajcevic, "Glioma proteomics: status and perspectives," Journal of Proteomics, vol. 73, no. 10, pp. 18231838, 2010.

[206] C. Vincke and S. Muyldermans, "Introduction to heavy chain antibodies and derived Nanobodies," Methods in Molecular Biology, vol. 911, pp. 15-26, 2012.

[207] Y.-J. Jou, C.-D. Lin, C.-H. Lai et al., "Proteomic identification of salivary transferrin as a biomarker for early detection of oral cancer," Analytica Chimica Acta, vol. 681, no. 1-2, pp. 41-48, 2010.

[208] J. A. Kooren, N. L. Rhodus, C. Tang, P. D. Jagtap, B. J. Horrigan, and T. J. Griffin, "Evaluating the potential of a novel oral lesion exudate collection method coupled with mass spectrometrybased proteomics for oral cancer biomarker discovery," Clinical Proteomics, vol. 8, no. 1, article 13, 2011.

[209] U. J. E. Thiel, R. Feltens, B. Adryan et al., "Analysis of differentially expressed proteins in oral squamous cell carcinoma by MALDI-TOF MS," Journal of Oral Pathology and Medicine, vol. 40, no. 5, pp. 369-379, 2011.

[210] C. T. Viet and B. L. Schmidt, "Understanding oral cancer in the genome era," Head \& Neck, vol. 32, no. 9, pp. 1246-1268, 2010.

[211] T. Shpitzer, G. Bahar, R. Feinmesser, and R. M. Nagler, "A comprehensive salivary analysis for oral cancer diagnosis," Journal of Cancer Research and Clinical Oncology, vol. 133, no. 9, pp. 613-617, 2007.

[212] S. A. Kawas, Z. H. A. Rahim, and D. B. Ferguson, "Potential uses of human salivary protein and peptide analysis in the diagnosis of disease," Archives of Oral Biology, vol. 57, no. 1, pp. 1-9, 2012.

[213] R. Nagler, G. Bahar, T. Shpitzer, and R. Feinmesser, "Concomitant analysis of salivary tumor markers-a new diagnostic tool for oral cancer," Clinical Cancer Research, vol. 12, no. 13, pp. 3979-3984, 2006.

[214] E. J. Franzmann, E. P. Reategui, F. Pedroso et al., "Soluble CD44 is a potential marker for the early detection of head and neck cancer," Cancer Epidemiology Biomarkers - Prevention, vol. 16, no. 7, pp. 1348-1355, 2007.

[215] T. Shpitzer, Y. Hamzany, G. Bahar et al., "Salivary analysis of oral cancer biomarkers," British Journal of Cancer, vol. 101, no. 7, pp. 1194-1198, 2009.

[216] S. Hu, M. Arellano, P. Boontheung et al., "Salivary proteomics for oral cancer biomarker discovery," Clinical Cancer Research, vol. 14, no. 19, pp. 6246-6252, 2008. 


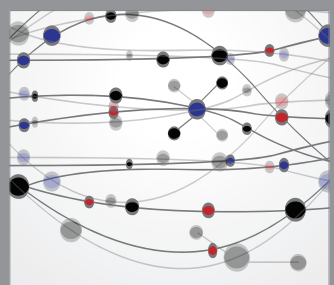

The Scientific World Journal
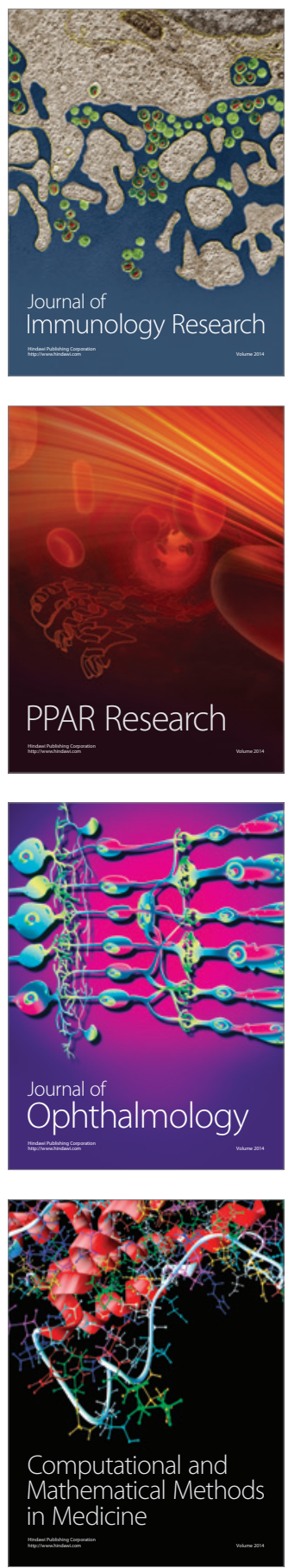

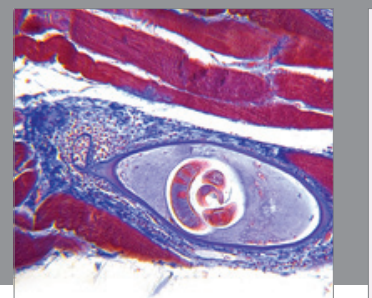

Gastroenterology

Research and Practice
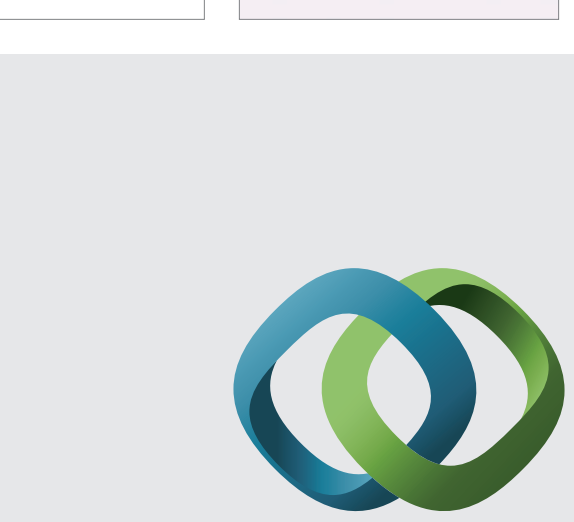

\section{Hindawi}

Submit your manuscripts at

http://www.hindawi.com
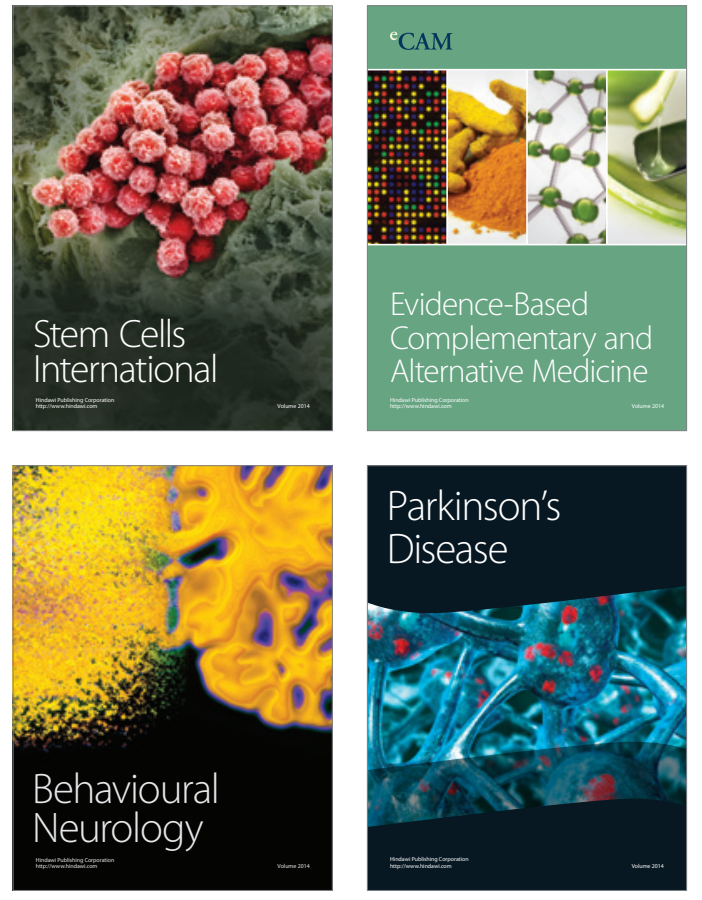
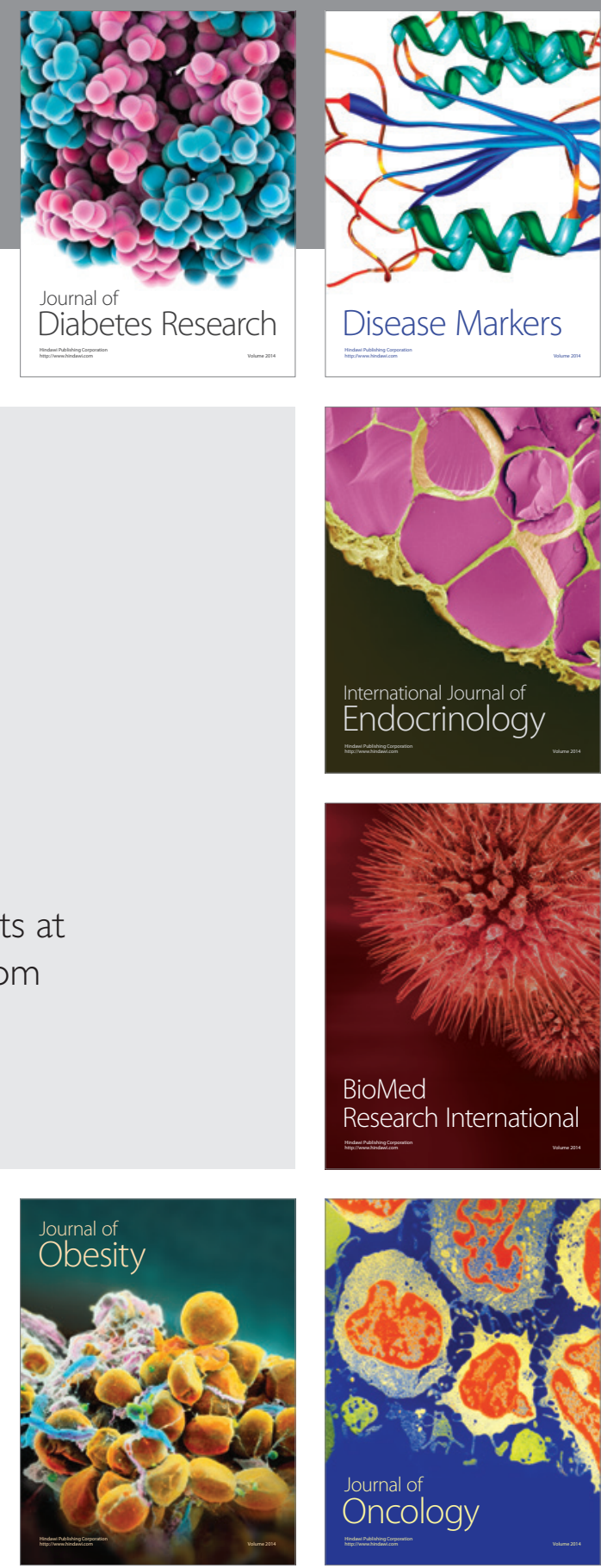

Disease Markers
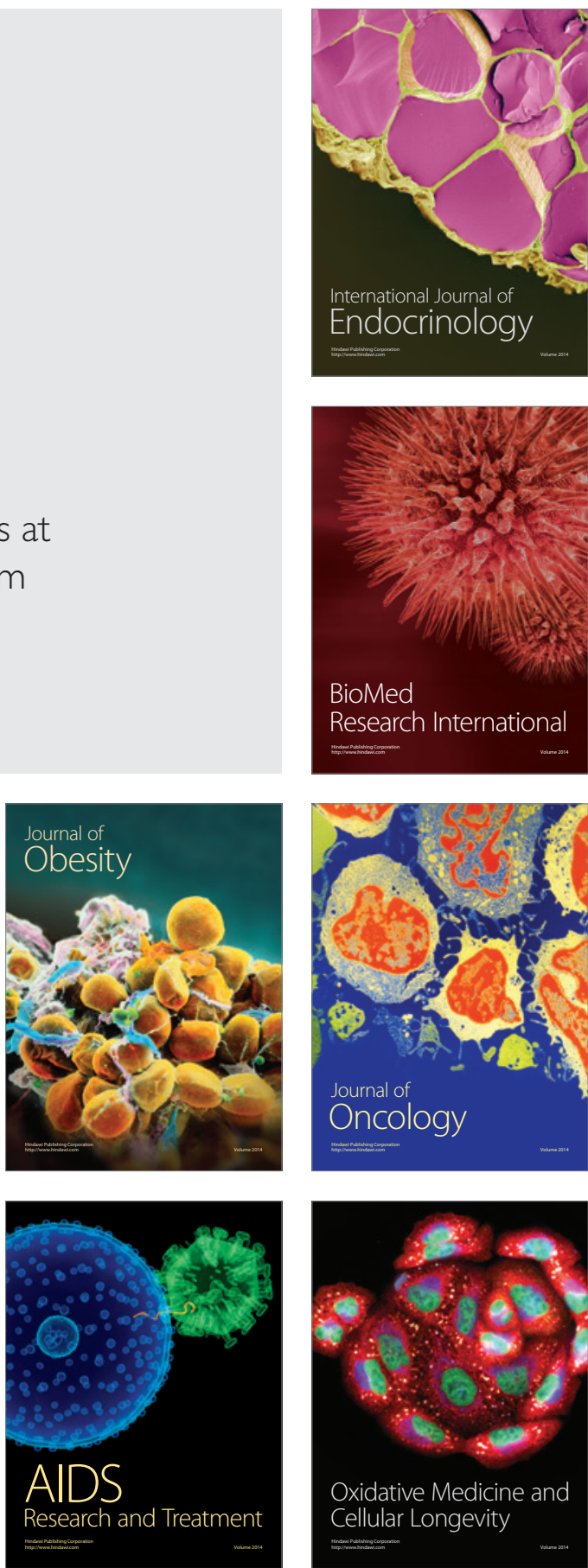